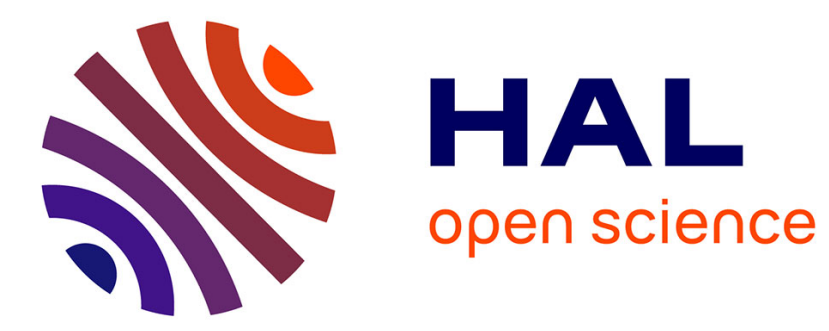

\title{
Mesoscale variability of phytoplankton and of new production: Impact of the large scale nutrient distribution
}

\author{
Marina Lévy
}

\section{- To cite this version:}

Marina Lévy. Mesoscale variability of phytoplankton and of new production: Impact of the large scale nutrient distribution. Journal of Geophysical Research, 2003, 108 (C11), pp.3358. 10.1029/2002JC001577 . hal-00153678

\section{HAL Id: hal-00153678 https://hal.science/hal-00153678}

Submitted on 27 Jan 2021

HAL is a multi-disciplinary open access archive for the deposit and dissemination of scientific research documents, whether they are published or not. The documents may come from teaching and research institutions in France or abroad, or from public or private research centers.
L'archive ouverte pluridisciplinaire HAL, est destinée au dépôt et à la diffusion de documents scientifiques de niveau recherche, publiés ou non, émanant des établissements d'enseignement et de recherche français ou étrangers, des laboratoires publics ou privés. 


\title{
Mesoscale variability of phytoplankton and of new production: Impact of the large-scale nutrient distribution
}

\author{
Marina Lévy \\ Laboratoire d'Océanographie Dynamique et de Climatologie, Institut Pierre Simon Laplace, Université Pierre et Marie Curie, \\ Paris, France \\ Received 2 August 2002; revised 11 June 2003; accepted 1 September 2003; published 22 November 2003.
}

[1] Concomitance at the mesoscale between doming isopycnals and phytoplankton maxima is often observed. A different situation is sometimes revealed by satellite images, where chlorophyll varies at the submesoscale. These two situations are rationalized using numerical simulations of interactive oceanic eddies, in the standard situation where they result from baroclinic instability. The driving parameter is found to be the nutrient distribution in the region where the eddies are formed. It is shown that the existence of a large-scale horizontal gradient is a sufficient condition for observing phytoplankton maxima within the eddies. The proposed mechanism is based on the direct horizontal cascade and involves horizontal transport. This mechanism is different from eddy pumping, which involves vertical transport, but leads to similar distributions of nutrients, phytoplankton, and density at the eddy scale. When vertical gradients are dominant, the regime is that of small-scale nutrient injection. In this regime, eddy-induced upwelling and associated nutrient transport occur on a scale one order of magnitude below the eddy scale. In both regimes, new production resembles vorticity and displays energetic small-scale features. On the contrary, phytoplankton distribution shows different characteristics depending on the regime. In the absence of horizontal gradients, submesoscale upwelling and subsequent stirring lead to enhanced phytoplankton in vorticity filaments. Otherwise, when horizontal gradients prevail, phytoplankton is primarily driven by the horizontal cascade and resembles the mesoscale temperature field. Another important result is that small-scale subduction can contribute to the export and decrease new production. INDEX TERMS: 4853 Oceanography: Biological and Chemical: Photosynthesis; 4520 Oceanography: Physical: Eddies and mesoscale processes; 4842 Oceanography: Biological and Chemical: Modeling; KEYWORDS: dynamical/biological model, submesoscale upwelling, horizontal cascade

Citation: Lévy, M., Mesoscale variability of phytoplankton and of new production: Impact of the large-scale nutrient distribution, J. Geophys. Res., 108(C11), 3358, doi:10.1029/2002JC001577, 2003.

\section{Introduction}

[2] It has been recognized for some time that mesoscale dynamics are responsible for vertical nutrient supply to the upper ocean [Jenkins, 1988; Falkowski et al., 1991]. A number of observations have shown that phytoplankton is often more abundant within doming eddies than in adjacent waters [Allen et al., 1996; Pinca and Huntley, 2000; McNeil et al., 1999; McGillicuddy et al., 1998, 1999, 2001; Longhurst, 2001]. A mechanism has been proposed to explain these observations [Yentsch and Phinney, 1985; McGillicuddy et al., 1999], often referred to as eddy pumping. It can be conceptualized by considering a density surface with mean depth at the level of the euphotic zone. Since first-mode cyclonic mesoscale structures have doming isopycnals at their center, the perturbation that they induce

Copyright 2003 by the American Geophysical Union. 0148-0227/03/2002JC001577 shoals density surfaces and, provided that nutrient distribution follow the isopycnals, lift nutrients into the euphotic zone. Conversely, isopycnal perturbations associated with first-mode anticyclones are a hollow at their center, and cannot supply nutrients to the euphotic layer. On the basis of theoretical arguments, another route for nutrient supply has been put forward to explain biological enhancement at the mesoscale that involves eddy-induced horizontal transport [Williams and Follows, 1998, 2003]. This mechanism could be a special case of Abraham's [1998] scenario in which plankton patchiness is interpreted as the consequence of the classical direct horizontal cascade (production of smaller and smaller scales by mesoscale eddies). In Abraham's scenario, nutrients, which are injected at large scales within the euphotic layer, are subsequently affected by this cascade process that occurs at a timescale usually larger than the e-folding time of phytoplankton growth.

[3] High-resolution sea color satellite images reveal another type of situation, where the phytoplankton field is dominated by small-scale features (small-scale or submeso- 
scale meaning small in comparison with the scale of the eddies) [Garcia-Moliner and Yoder, 1994; Yoder, 2000; Abraham et al., 2001; Longhurst, 2001; Mahadevan and Campbell, 2002; Davenport et al., 2002; Santoleri et al., 2003]. A previous modeling process study [Lévy et al., 2001, hereinafter referred to as LKT] was aimed at rationalizing this situation. In LKT, a classical physical context was set up with a high-resolution primitive equation ocean model, in which mesoscale eddies result from the nonlinear equilibration of an unstable baroclinic jet. This set up allowed tracking the formation of both a cyclonic and an anticyclonic eddy. The physical model was coupled with an ecosystem model. LKT suggest that the small-scale features in the phytoplankton field result from small-scale nutrient injection, characteristic of frontogenesis [Wang, 1993; Spall, 1995, 1997; Klein et al., 1998], in specific regions where the horizontal stirring is strong. In the situation explored in LKT, the leading mechanism is not eddy pumping but small-scale nutrient injection. Actually at the scale of the eddy, a situation opposite to eddy pumping prevails. In agreement with the nonlinear dynamics of baroclinic jets, the formation process of the anticyclone is associated with an average upward transport (squeezing), while the formation of the cyclone is accompanied by a downward transport (stretching). Consequently, the anticyclone is more productive than the cyclone. Such a situation has been encountered in the Azores front region by Perez et al. [2003], in the Northeast Atlantic by C. Fernandez et al. (Impact of mesoscale features on seasonal distribution of nitrate in the northeast Atlantic Ocean, submitted to Journal of Marine Systems, 2003, hereinafter referred to as Fernandez et al., submitted manuscript, 2003), and similar model results were obtained by Spall and Richards [2000]. It is worthwhile to emphasize that the processes of squeezing and stretching do not imply changes in the usual thermohaline structure of the eddies (i.e., first-mode cyclonic eddies have doming isopycnals in their center, and are seen with a surface depression in TOPEX/Poseidon imagery, with the inverse situation for first-mode anticyclonic eddies).

[4] This study is aimed at differentiating the above observed situations, in the standard situation where eddies result from the baroclinic instability of a mean current. One question which arises and that has received little attention up to now is how the large-scale distribution or injection of nutrients affects the variability of new production, and ultimately the phytoplankton. More precisely, this study aims at answering the following questions: What are the dynamical processes into play, and can they be distinguished on the basis of a simple criterion on the large-scale nutrient distribution? How does the large-scale nutrient distribution ultimately control the variability of phytoplankton in a mesoscale eddy field? Is the resulting variability of the biomass the same as that of new production? An underlying goal is to shed some light on the interpretation of concomitant observations of temperature and chlorophyll, either as remotely sensed or from moorings. While temperature (or sea level high) and chlorophyll (or nitrate) may show good correlation at the mesoscale, it is not always the case. The reasons for this existence of or lack of correlation are examined in light of the large-scale temperature/nutrient relationship. These questions also stem from numerical and theoretical results in ocean physics. Klein and Hua [1990] examined the emergence and evolution of a mesoscale variability in sea surface temperature triggered by a mixed layer deepening. Their results suggest that the scales of variability of a tracer depend on its initial largescale features.

[5] The above questions are addressed in the model set up used in LKT, which provide an accurate representation of the mesoscale and submesoscale physics. The intention is to create a framework to characterize the nature of the effect of the large-scale nutrient distribution on the space variability of phytoplankton and new production. For that purpose, the model is run with four different initial nutrient fields and the different model runs are compared. In the experiments described in LKT (as well as by Spall and Richards [2000]), nutrients are assumed to be distributed as a function of depth rather than density on the vertical, which may explain why eddy pumping does nor prevail. In order to test that hypothesis, density versus depth dependence in the nutrient field is investigated. Then, the influence of a large-scale nutrient horizontal gradient in the euphotic layer is examined. This situation allows both the horizontal cascade process and small-scale vertical nutrient injection to occur. The LKT experiment only addressed the case of an oligotrophic regime, and focused on eddies during their formation process. In this work, various trophic regimes are explored, as well as the formation, propagation and decay of oceanic eddies, and the effect of heat fluxes. However, quantification of the impact of eddies on biogeochemical fluxes remains difficult since so many factors are at play: the turbulent kinetic energy, the age of the eddies, the heat flux, the stratification, the depth of the nitracline. A systematic sensitivity study of all of these factors has not been done, although many experiments were carried out.

[6] On the basis of these simulations, I propose a scenario where the increase of phytoplankton biomass within cyclones involves essentially horizontal transport. These experiments also illustrate the robustness of the mechanisms proposed in LKT. In particular, small-scale nutrient injection is found to occur during the formation and decay of the eddies and to drive the scales of variability of new production in most cases. However, phytoplankton variability depends on the initial large-scale nutrient distribution.

[7] The paper is organized as follows. In section 2 the model setup and the various model experiments are presented. Section 3 describes the results of the experiments, and section 4 is the discussion.

\section{Model Setup}

\subsection{Dynamical Model Setup}

[8] The dynamical regime addressed in this study is that of typical interactive midocean eddies, scaled by the first Rossby radius of deformation, with $\mathcal{O}(1)$ Rossby number, and with the vertical structure of the first baroclinic mode (cyclones characterized by doming isopycnals in their core, and anticyclones by shoaling isopycnals).

[9] Several studies suggest that these first-mode baroclinic eddies are formed through the mechanism of baroclinic instability, and constitute the primary eddy source term everywhere in the ocean (although other processes may become locally important). Stammer [1998] reaches this 
conclusion by highlighting the close association of the observed eddy kinetic energy distribution estimated from TOPEX/Poseidon altimetric measurements with the mean baroclinic flow, and the fact that eddy scales are strongly correlated with the first-mode Rossby radius of deformation. Wunsch [1997] comes to a similar conclusion from a completely independent analysis in terms of dynamical modes of globally distributed current meter data. Paillet [1999], from a series of float trajectories, identifies central water vortices in the Eastern Atlantic as the instability of the North Atlantic current, the Azores Current and the poleward eastern boundary current. Spall [2000] shows that baroclinic instability of nonzonal weak flows might generate strong mesoscale eddies. His results suggest that within the interior of oceanic gyres, away from strong boundary currents, baroclinic instability is also the main formation process of eddies.

[10] On the basis of the above studies, the model is set up so that eddy energy feeds on an initial large-scale potential energy reservoir. A primitive equation ocean model (OPA) [Madec et al., 1999], set at high horizontal resolution $(2 \mathrm{~km})$, is used to simulate an initially straight front breaking apart into first-mode baroclinic eddies, in a zonally periodic $\beta$ plane channel. The basic state is a uniform potential vorticity zonal jet, centered at $30^{\circ} \mathrm{N}$, in geostrophic and hydrostatic balance resulting from the interpolation between a northern and a southern density profile, representative of the North Atlantic (see LKT).

[11] The mean density profile yields a first baroclinic Rossby radius of deformation of $30 \mathrm{~km}$. The most unstable wave has a wavelength of $160 \mathrm{~km}$, a growth rate of approximately (15 days $)^{-1}$ and is mainly captured by the first baroclinic mode (whose zero crossing is at a depth of $500 \mathrm{~m}$ ). The initial density field is perturbed with the fastest growing unstable mode. The domain geometry is a channel $1000 \mathrm{~km}$ wide, $160 \mathrm{~km}$ long, and $4000 \mathrm{~m}$ deep. The domain length is chosen to correspond to one wavelength of the most unstable baroclinic wave. For the sake of simplicity, density is assumed to be a linear function of temperature. Horizontal mixing of density and momentum is included through biharmonic friction terms which insure numerical stability by selectively dissipating the smallest horizontal scales of all fields. The dissipation coefficient is tuned to the smallest possible value to avoid numerical noise, $0.5 \times$ $10^{9} \mathrm{~m}^{4} \mathrm{~s}^{-1}$. Most experiments are forced with a positive net heat flux of $100 \mathrm{~W} \mathrm{~m}^{-2}$ and a penetrative solar flux of $250 \mathrm{~W} \mathrm{~m}^{-2}$, which are average daily values for spring to summer conditions (diurnal variations are not accounted for in this study). One experiment is also presented with a negative net heat flux of $-100 \mathrm{~W} \mathrm{~m}^{-2}$ and a solar flux of $100 \mathrm{~W} \mathrm{~m}^{-2}$, which is representative of fall conditions.

\subsection{Simulated Dynamics}

[12] Eddies are spun up in 20 days, and the experiments last for two months (instead of one month in LKT). During the first few days of the simulation (days 1 to 12), meanders develop at the initial frontal jet. These meanders grow and break up into eddies. After 20 days the nonlinear regime is fully attained and mesoscale eddies have developed. The decay period starts after 30 days.

[13] The inspection of a particular scene after 42 days of simulation (Figure 1) reveals three dominant mesoscale structures: in the south, a small, cold, well-formed cyclonic eddy $(\mathrm{C} 1)$; in the north, a large, warm, strongly distorted anticyclone (AC1), and a smaller anticyclone in formation (AC2).

[14] The formation and decay of these eddies can be visualized in Figure 2, which shows the time evolution of zonal enstrophy. The meridional development of enstrophy trails correspond to the fingerprints of $\mathrm{C} 1$ and $\mathrm{AC} 1$, which are formed around day 20 and then detach. It can be seen that $\mathrm{C} 1$ is an isolated structure (the contour of the southern trail is very accurate). It has a diameter of roughly $50 \mathrm{~km}$, and propagates over approximately $250 \mathrm{~km}$ during the experiment. On the other hand, AC1 strongly interacts with its surroundings (the northern trail contour is less clear). Its diameter is approximately $100 \mathrm{~km}$, but its original circular structure is strongly distorted by the interactions with its surroundings. AC1 also covers a distance of roughly $250 \mathrm{~km}$ during the experiment. AC2 is identifiable close to the center of the domain starting from day 30, and does not propagate much. The slow decrease of enstrophy after 30 days marks the start of the decay period. Between days 30 and 60 , maximum enstrophy in $\mathrm{C} 1$ decreases by $54 \%$, in $\mathrm{AC} 1$ by $34 \%$ and in $\mathrm{AC} 2$ by $39 \%$.

[15] Comparisons with observations of midlatitude jets and eddies in the North Atlantic indicate that the model produces a realistic representation of midlatitude mesoscale dynamics. Days 1 to 20 of the run provide a schematic picture of eddies detaching from a meandering jet, with cyclones to the South and anticyclones to the north. The numerical eddies that propagate and decay during days 20 to 60 of the simulation have diameters $(50$ to $100 \mathrm{~km}$ ), maximum horizontal velocities (up to $0.9 \mathrm{~m} \mathrm{~s}^{-1}$ ), associated vertical velocities (up to $50 \mathrm{~m} \mathrm{~d}^{-1}$ ), and propagation speed $\left(\approx 4 \mathrm{~km} \mathrm{~d}^{-1}\right.$ to the west) comparable to observations in the North Atlantic [Richardson, 1983; Pollard and Regier, 1992; Richardson, 1993; Stammer, 1997, 1998; Martin and Richards, 2001; Glover et al., 2002].

[16] Besides the mesoscale structures, Figure 1 also reveals the presence of thin submesoscale relative vorticity patterns. One important aspect of the patterns is that these submesoscale vorticity filaments are closely related to mesoscale eddies. Some of them surround eddies, as the positive vorticity filament $\mathrm{F} 1$ that shields $\mathrm{AC} 1$. Others are ejected by the eddies and are responsible for chaotic advection, such as filament F2 being ejected by $\mathrm{AC} 1$, and some are more isolated like F3. As discussed in LKT, these submesoscale vorticity structures are the signature near the surface of active small-scale frontal dynamics [Davies-Jones, 1991; Spall, 1997]. They are associated with intense vertical velocities $\left(\approx 50 \mathrm{~m} \mathrm{~d}^{-1}\right)$, that are dominant in the first $200 \mathrm{~m}$. Vorticity filaments that surround the eddies are known to act as dynamical barriers that preserve their coherence and increase their lifetime [Mariotti et al., 1994]. Eddies decay when these dynamical barriers disappear because of dissipation (case of $\mathrm{C} 1$ ), or when filaments are ejected (case of $\mathrm{AC} 1$ ). In this second case, which occurs when the eddy is interacting with other eddies, the eddy decay is accompanied by vertical movements.

[17] The scales of variability of vorticity and SST can be quantified by looking at their respective variance spectra (Figure 3). SST displays a spectrum slope of $\mathrm{k}^{-3}$ and 

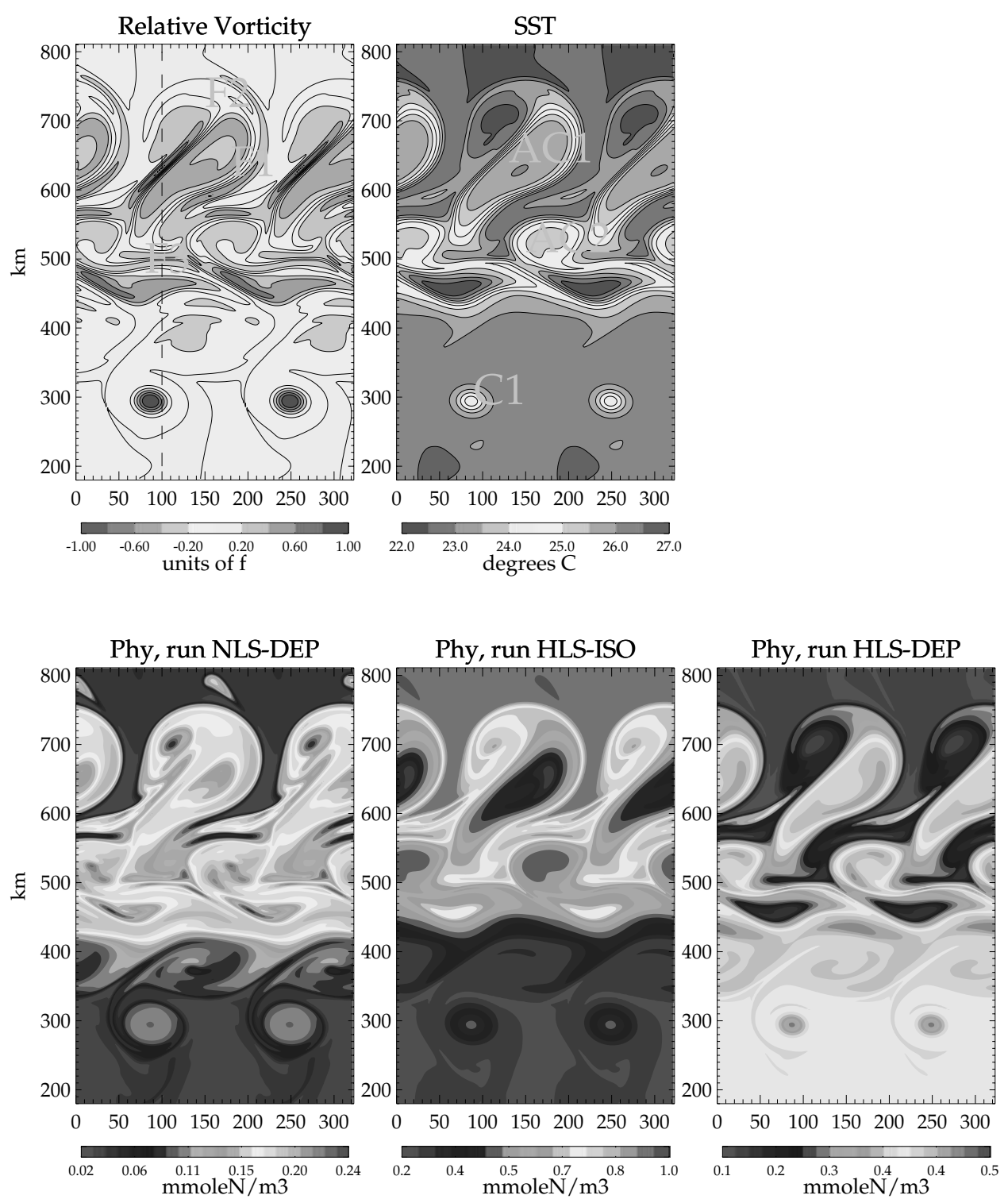

Figure 1. Model snapshots at day 42. For clarity and taking advantage of the zonal periodicity the domain is artificially doubled in length in its zonal direction. Meridional bands $0-200$ and $800-1000 \mathrm{~km}$ are not affected by the eddies and are withdrawn from the analysis. Surface fields are shown, except for "Phy, run NLS-DEP", which shows the phytoplankton concentration averaged over the depth range 0 $100 \mathrm{~m}$. The same dynamics are used in runs NLS-DEP, HLS-ISO, and HLS-DEP. The differences in the resulting distribution of phytoplankton are related to different nitrate initializations. Note that the space scales of variability of temperature (density) and relative vorticity are quite different. In run NLS-DEP, phytoplankton space variability resembles that of vorticity (i.e., dominated by submesoscale features), while in runs HLS-ISO and HLS-DEP, it resembles the variability of SST (i.e., dominated by mesoscale features). See color version of this figure at back of this issue.

therefore energetic large scales. The vorticity field has a less steep spectral slope $\left(\mathrm{k}^{-2}\right)$ and as such contains more energetic small scales. Values of these slopes indicate that the submesoscale turbulence is accurately reproduced by the model [Held et al., 1995; Klein et al., 1998].

\subsection{Biogeochemical Model Setup and Model Experiments}

[18] The biological model consists of six prognostic variables (nitrate, ammonium, phytoplankton, zooplankton, detritus, and dissolved organic matter), which are freely advected by the flow and entrained by vertical mixing (See LKT for a complete description of the model). Phytoplankton and zooplankton proper mobility are not accounted for in this model. The model explicitly enables the distinction between new production, based on nitrate, and regenerated production, based on ammonium. In this work, emphasis is put on the analysis of new production, which is directly influenced by the dynamics.

[19] Several experiments are performed that differ in the way nitrate is initialized (Table 1). Unless specified, the dynamics are exactly the same for all experiments. 


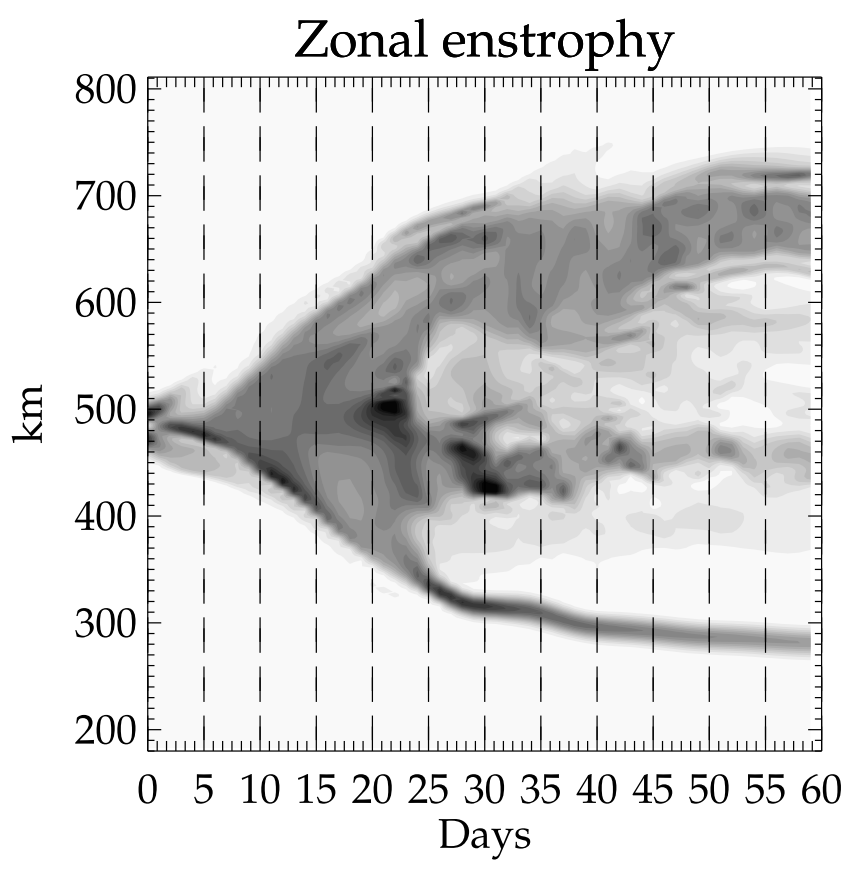

Figure 2. Time evolution of surface enstrophy, averaged along the zonal direction.

[20] Nitrate distribution at depth results from the combination of isopycnal transport and remineralization, and two extreme situations can be imagined, in which it would result entirely from either one or the other. If only isopycnal transport is at play, nitrate concentration follows isopycnal surfaces. This hypothesis is fundamental for eddy pumping to occur. In the second case, and assuming depth-dependent remineralization, nitrate concentration follows depth surfaces, a configuration used in LKT and Spall and Richards [2000]. Situations close to each of these two extreme cases have been reported in the North Atlantic ocean. Pelegri and Csanady [1991] find homogeneous nitrate concentrations along isopycnals in the Gulf Stream region, below the euphotic layer. In contrast, in the Northeastern Atlantic, nitrate surfaces flatter than the isopycnals have been
Table 1. Model Experiments

\begin{tabular}{lcccc}
\hline \multicolumn{1}{c}{ Runs } & $\begin{array}{c}\text { Initial Nitrate } \\
\text { Field }\end{array}$ & $\begin{array}{c}\text { Large-Scale } \\
\text { Gradient }\end{array}$ & $\begin{array}{c}\text { Depth } \\
\text { Distribution }\end{array}$ & $\begin{array}{c}\text { Trophic } \\
\text { Regime }\end{array}$ \\
\hline NLS-DEP & NLS-DEP & no & depth & oligo \\
NLS-ISO & NLS-ISO & no & iso & oligo \\
HLS-ISO & HLS-ISO & yes & iso & bloom-oligo \\
HLS-DEP & HLS-DEP & yes & depth & bloom-oligo \\
NLS-DEP-F & NLS-DEP & no & depth & oligo-fall \\
\hline
\end{tabular}

reported [Arhan et al., 1994; Fernandez et al., submitted manuscript, 2003].

[21] In the euphotic layer, nutrients are often depleted, in which case the nitrate distribution does not display a largescale horizontal gradient. Only during transient prebloom conditions is nitrate observed at the surface, and it can exhibit large-scale gradients. At midlatitudes, these surface gradients are the fingerprint of the gradient at depth, and can also result from variability in mixed layer winter entrainment [Glover and Brewer, 1988; Fernandez et al., submitted manuscript, 2003].

[22] On this basis, four initial nitrate distributions are considered (NLS-ISO, NLS-DEP, HLS-ISO, and HLSDEP). The suffixes ISO and DEP designate the nitrate distribution below the euphotic layer and refer to whether the vertical distribution follows the isopycnal surfaces (ISO) or the depth surfaces (DEP). The prefix NLS stands for no large-scale gradient in the euphotic layer. In the NLS situation, nutrients are depleted in the first $100 \mathrm{~m}$ all over the domain. For the contrary, the suffix HLS for horizontal large-scale indicates the existence of a large-scale crossfrontal gradient in the euphotic layer. Since the ISO nitrate distributions follow the isopycnals, nitrate and density are linearly related below the euphotic layer in NLS-ISO and HLS-ISO. This is actually how NLS-ISO and HLS-ISO were constructed. The linear regression $\left(\mathrm{NO}_{3}=25.29-\right.$ $1.006 \mathrm{~T}$, with $\mathrm{NO}_{3}$ the nitrate concentration in mmole $\mathrm{m}^{-3}$ and $\mathrm{T}$ the temperature in degrees Celsius) is inferred from North Atlantic climatological data (Levitus nitrate and temperature data between $30 \mathrm{~N}$ and $40 \mathrm{~N}$ in the main thermocline). The DEP distributions are derived from the ISO ones (Figure 4). Since isopycnals outcrop in the north,
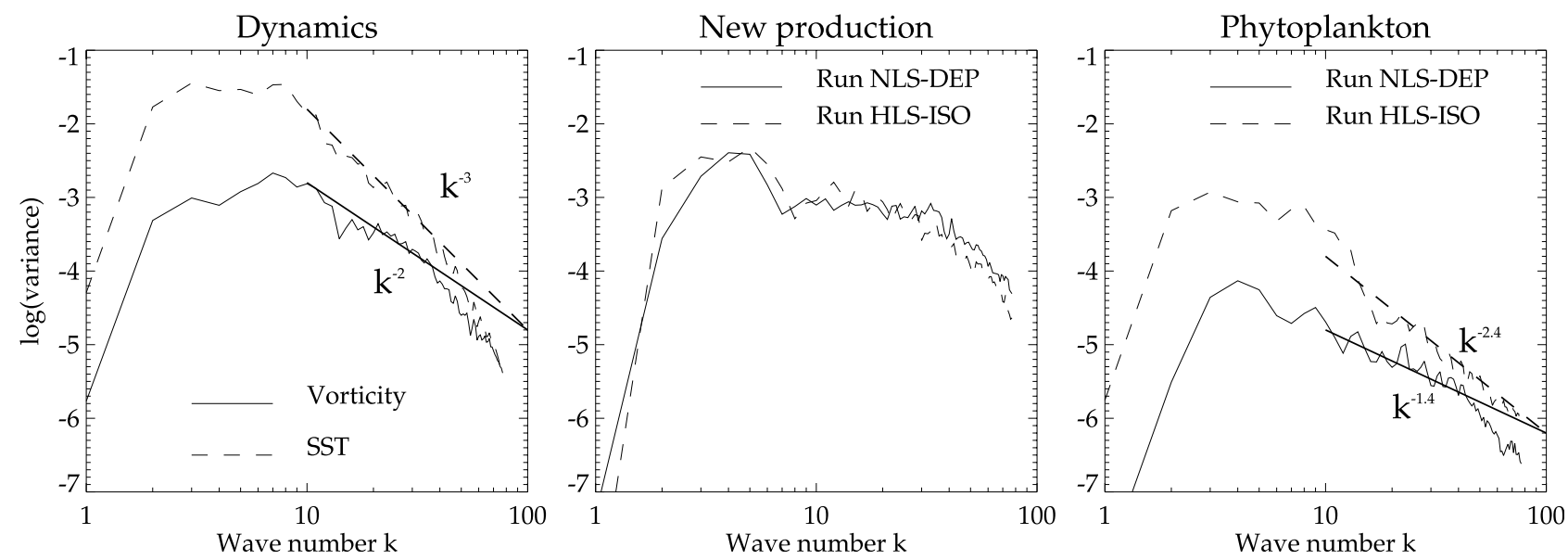

Figure 3. Wave number spectrum of the fields displayed on Figure 1 and of the corresponding new production fields. Spectra of relative vorticity, SST, and phytoplankton are characterized by a power law as $\mathrm{k}^{n}$ between the mesoscale peak at $100-200 \mathrm{~km}$ and a scale of $10 \mathrm{~km}$. 

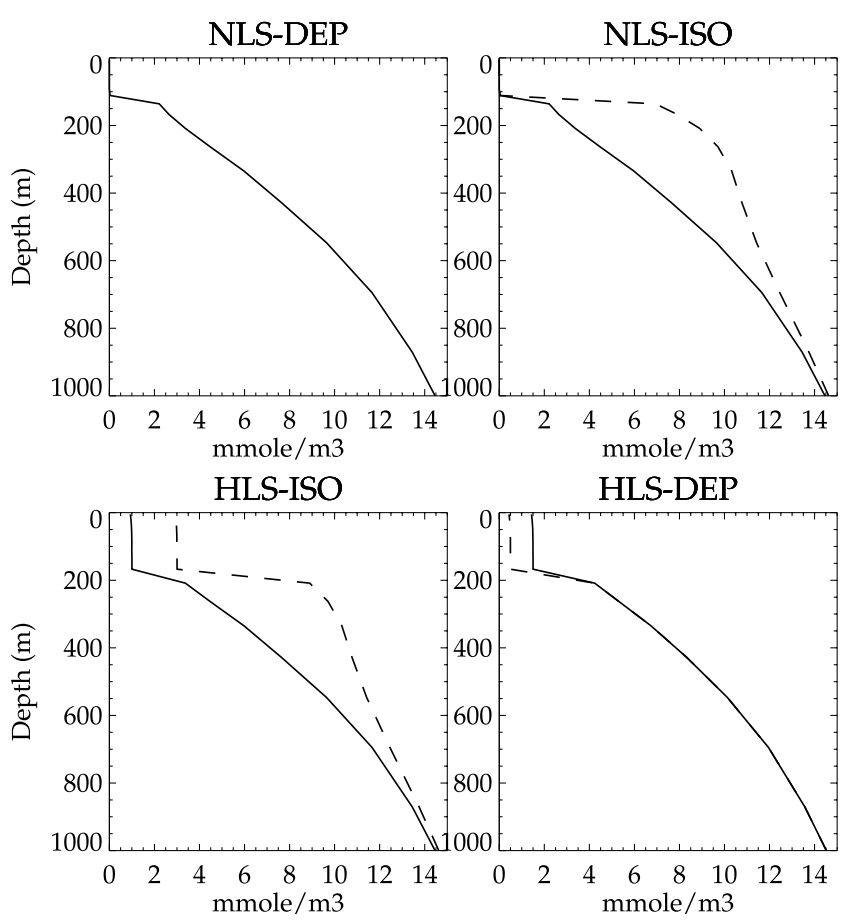

Figure 4. The northern (dotted line) and southern (solid line) nitrate profiles in the four initial nitrate distributions used to run the model. By definition the two profiles coincide below the euphotic layer in the DEP cases.

nutrient concentrations at a given depth are higher in the north than in the south in the ISO case, but are constant in the DEP case. At the surface, there is more nitrate on the north side $\left(3\right.$ mmole $\left.\mathrm{m}^{-3}\right)$ than on the south side ( $1 \mathrm{mmole} \mathrm{m}^{-3}$ ) in HLS-ISO, reflecting the meridional nitrate gradient at depth. Such a situation could result from a large-scale injection because of a convective event that would have homogeneously deepened the mixed layer. In HLS-DEP the opposite situation is explored (initially, there is more nitrate available in the south, 1.5 mmole $\mathrm{m}^{-3}$, than in the north, 0.5 mmole $\mathrm{m}^{-3}$ ). This situation can occur when the southern side is significantly less stratified than the northern side. In that case, the mixed layer entrainment due to convection is deeper in the south than in the north. These nitrate surface values fall into the range encountered during prebloom conditions at midlatitudes in the North Atlantic (i.e., BATS, NABE).

[23] The other biogeochemical variables are initialized with low values $\left(0.01\right.$ to $\left.0.1 \mathrm{mmole} \mathrm{m}^{-3}\right)$ in the euphotic layer. In the case of the NLS experiments, the basic state (i.e., in the absence of mesoscale activity) is an oligotrophic situation in steady state, with a subsurface phytoplankton concentration located at the base of the nitracline and sustained by weak nitrate diffusion. In the case of the HLS experiments, the initial state is that of prebloom conditions. Convection is assumed to have occurred prior to the experiment, and the water column is stabilized at the initiation of the run. The HLS experiment describes a bloom followed by a transition toward oligotrophy.

\section{Model Results}

\subsection{Case of the Absence of a Large-Scale Nutrient Gradient in the Euphotic Layer}

\subsubsection{Nitrate Following Depth Surfaces}

[24] When no large-scale gradient is present at the surface, which is typically the case of oligotrophic situations in which nitrate is depleted in the euphotic layer, the smallscale vertical nutrient inputs are the main source for phytoplankton growth. This situation is that of run NLSDEP. Figure 5 shows that the main impact of the dynamics associated with the mesoscale eddy field is to trigger nutrient input within the euphotic layer and to increase new production above its initially low value. Total new production (defined as the domain averaged new production rate) increases by a factor of three between day 1 and 30 $\left(0.2\right.$ to 0.6 mmoleN $\left.\mathrm{m}^{-2} \mathrm{~d}^{-1}\right)$, corresponding to the period of intensification of the eddies. It remains comparatively large $\left(0.4-0.5 \mathrm{mmoleN} \mathrm{m} \mathrm{m}^{-2} \mathrm{~d}^{-1}\right)$ during the period of decay of the eddies.

[25] As shown in LKT, the most striking result of this simulation is the strong heterogeneity of new production on
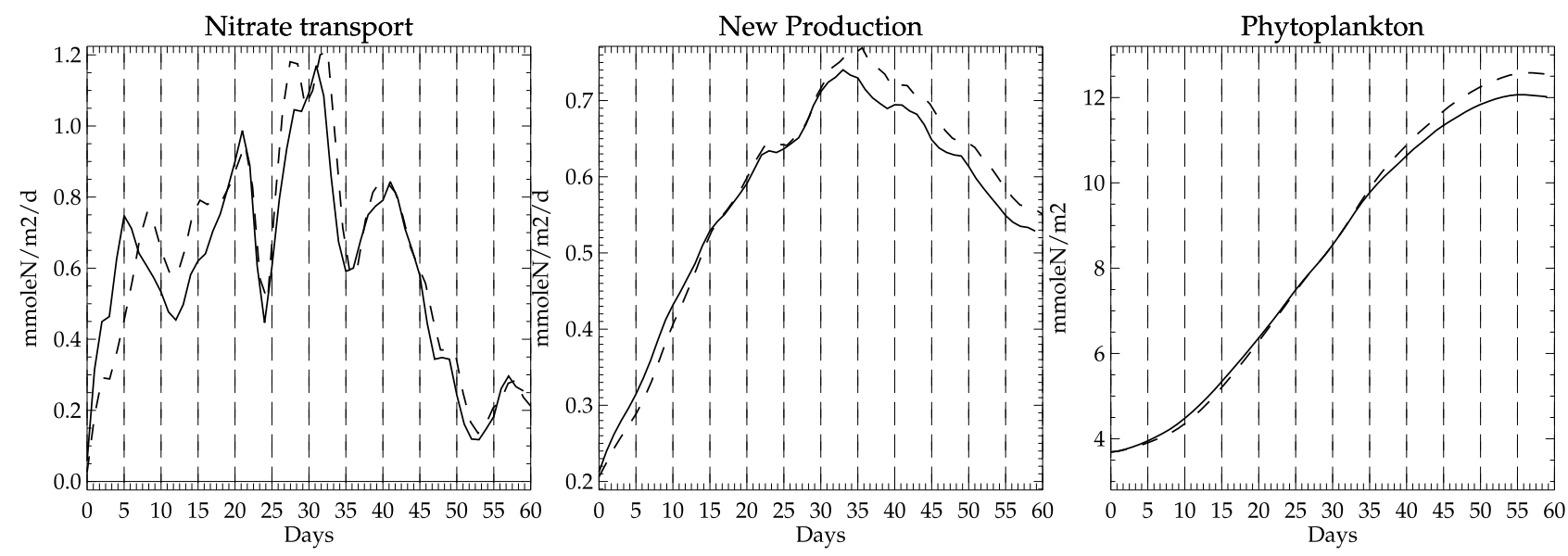

Figure 5. Time evolution of Nitrate transport (advection + diffusion), new production, and phytoplankton for run NLS-DEP (solid line) and run NLS-ISO (dotted line). Values are averages over the horizontal domain shown in Figure 1 and integrated over the first $100 \mathrm{~m}$ of the water column. 

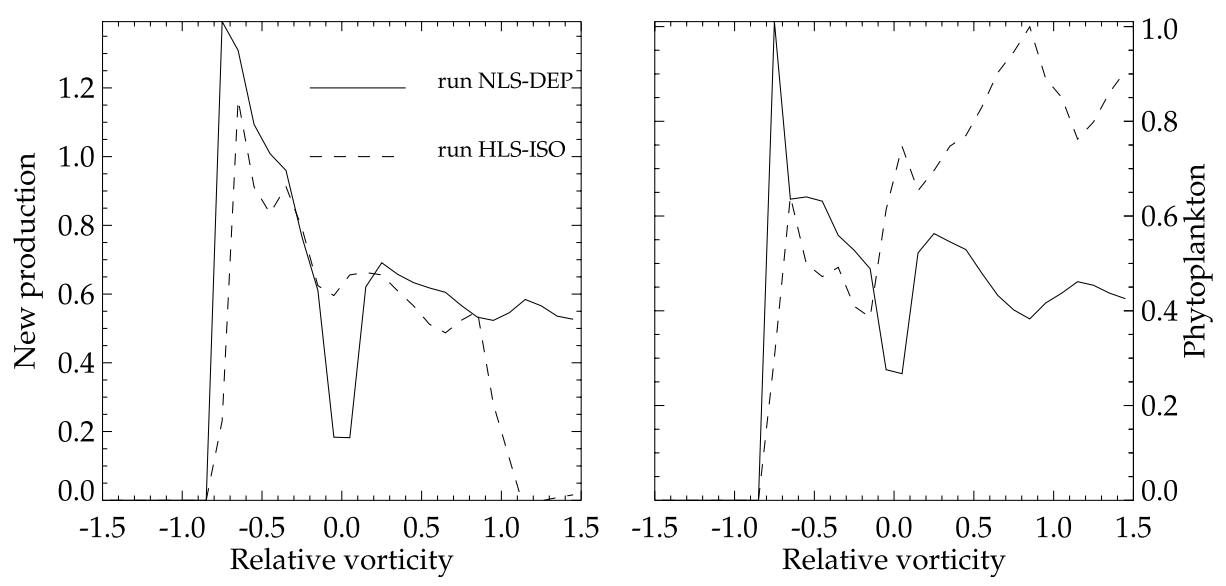

Figure 6. Plots of new production and phytoplankton versus vorticity for runs NLS-DEP (solid line) and HLS-ISO (dotted line). Values represent averages over vorticity bins of width $0.1 \mathrm{f}$. Data from days 10 to 60 of the runs are considered. Relative vorticity is in units of $\mathrm{f}$. New production units are mmole $\mathrm{m}^{-2} \mathrm{~d}^{-1}$. The averaged $0-100 \mathrm{~m}$ phytoplankton concentration is used for run NLS-DEP (case with a subsurface phytoplankton maximum), and the surface phytoplankton concentration is used for run HLSISO (case with a surface maximum). Phytoplankton are in dimensionless units (normalized by the maximum value obtained after the binning, i.e., $1.15 \mathrm{mmole} \mathrm{m}^{-3}$ for run HLS-ISO and $0.22 \mathrm{mmole} \mathrm{m}^{-3}$ for run NLS-DEP). New production is significantly enhanced in regions of strong negative relative vorticity in both runs. This is also the case for phytoplankton in run NLS-DEP but not in run HLS-ISO.

scales smaller than the mesoscale. More precisely, new production is enhanced in regions of strong vorticity gradients, particularly around mesoscale eddies and in vorticity filaments. Maximum new production is obtained within regions of strong negative vorticity, which are regions where upward vertical velocities due to frontogenesis prevail [Spall, 1997]. This can be seen in Figure 6, which shows a plot of new production against relative vorticity.

[26] In response to the increase in new production, phytoplankton develop during the course of the run (Figure 5). In this oligotrophic situation phytoplankton growth is entirely sustained by the injection of nutrients, which essentially occurs at small scales. Therefore phytoplankton patterns closely resemble those of new production, only a bit more stirred up by the flow. Hence, as for new production, phytoplankton are essentially found in filaments of negative vorticity (Figure 6) and mostly display submesoscale patterns (Figure 1). Maximum phytoplankton concentrations are found below the surface, at the base of the nitracline (Figure 7). Consequently, these small-scale phytoplankton patterns should not be detectable by a satellite. Finally, there is no obvious correlation between the phytoplankton and the SST patterns. Rather, phytoplankton variability resembles that of relative vorticity and displays energetic small scales (the spectrum slope of phytoplankton in run NLS-DEP is $\mathrm{k}^{-1.4}$; Figure 3).

\subsubsection{Nitrate-Following Isopycnal Surfaces}

[27] The impact of the distribution of nitrate below the euphotic layer is addressed by comparing the results of runs NLS-DEP and NLS-ISO. As mentioned before, the initial nitrate field in run NLS-ISO is such that nitrate follows the isopycnals below the euphotic layer, whereas in run NLS-DEP nitrate concentrations follow the depth surfaces. Results show that these different nitrate initializations lead to slightly different nitrate transport, but on whole barely affect total new production and total phyto- plankton (Figure 5). Moreover, the phytoplankton and new production distributions are very similar (they are not discernible to the eye). These results are not surprising, and can be understood by looking at the analytical formulation of vertical advection. The flux of nitrate into the euphotic layer due to vertical advection is equal to the vertical velocity multiplied by the nitrate concentration at the base of the euphotic layer (which coincides with the depth of the nitracline). Vertical velocity is the same for the two runs, and, as shown by Figure 4, nitrate concentrations at the base of the euphotic layer are very similar. They are only slightly stronger in the north in the case of run NLS-ISO, which is consistent with the slightly higher level of new production and of phytoplankton.

[28] There is no signature of eddy pumping, even in this more favorable experiment. Phytoplankton are more abundant (Figure 1) and closer to the surface in the anticyclonic eddies than in the cyclonic eddy (Figure 7). There is some biomass enhancement associated with $\mathrm{C} 1$ (Figure 7), but located at the rim of $\mathrm{C} 1$ (Figure 1) and due to submesoscale upwelling. The lack of evidence for eddy pumping in this simulation is all but confirmed by cross sections of nitrate (Figure 8). Down to approximately $400 \mathrm{~m}$, nitrate concentration contours subside within $\mathrm{Cl}$, and dome within $\mathrm{AC} 1$. Below the euphotic layer, nitrate turns out to be actually slightly positively correlated with temperature, which is a situation opposite to what would be expected from eddy pumping. This unusual distribution, mostly apparent in run NLS-DEP, is the consequence of the partiality of this work to totally discriminate between vertical and horizontal nutrient gradients in the initial conditions. It highlights that the dominant trend of this dynamics is not to align nutrients and density. Hence strong nutrient gradients are generated along isopycnal surfaces, and are particularly obvious below the euphotic layer. For instance, the vertical displacement of the second isopycnic level from the surface associated with 

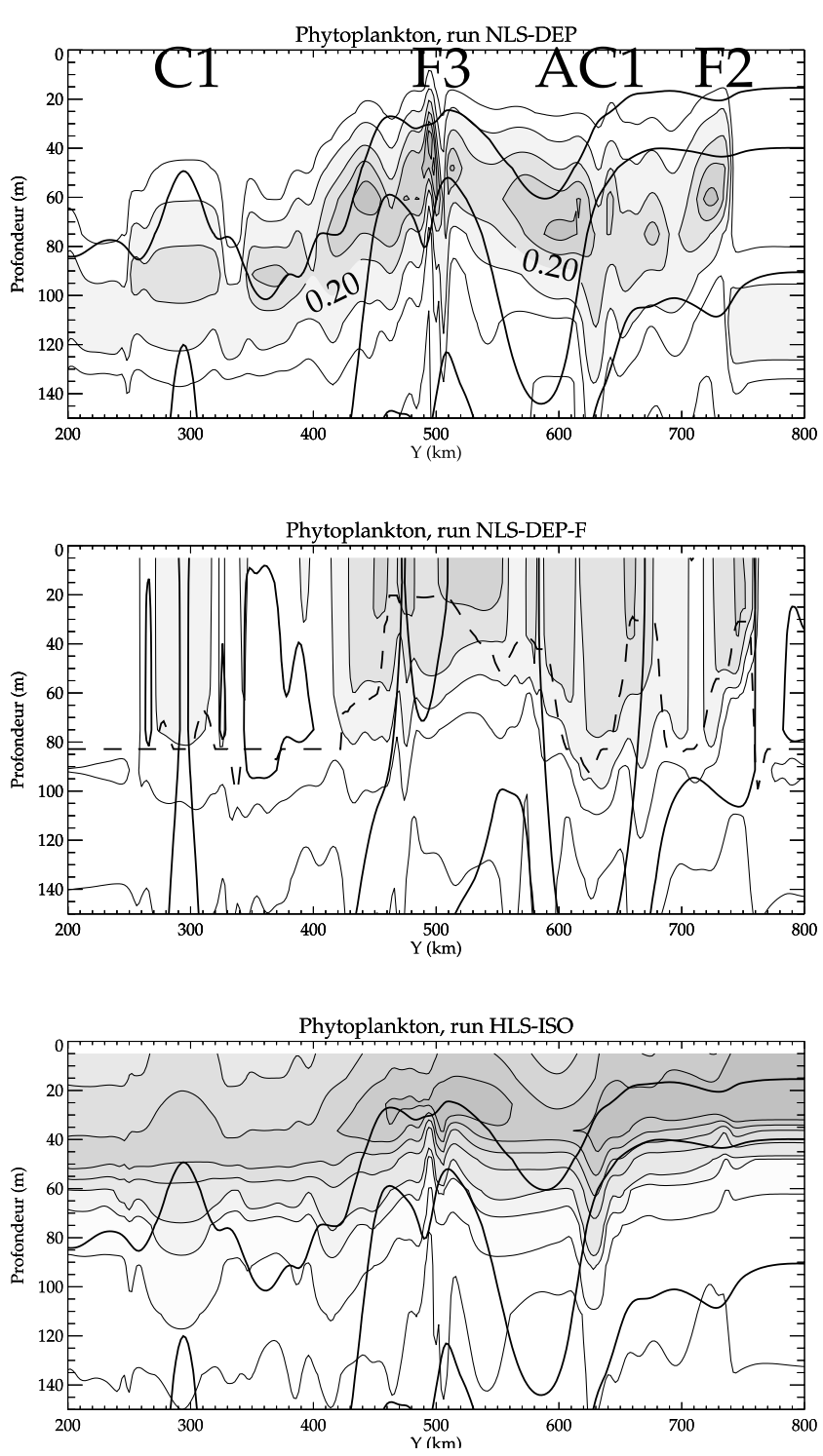

Figure 7. North-south vertical section of phytoplankton (grey shading) along $\mathrm{x}=100 \mathrm{~km}$ (snapshot at day 42) and for the first $150 \mathrm{~m}$. The section goes across cyclone $\mathrm{C} 1$, anticyclone $\mathrm{AC} 1$, and filaments $\mathrm{F} 2$ and $\mathrm{F} 3$ and is shown by the vertical dotted line on Figure 1. Contour values are 0.01, $0.05,0.1,0.2,0.3$, and $0.4 \mathrm{mmoleN} \mathrm{m}^{-3}$ for runs NLS-DEP and NLS-DEP-F and $0.003,0.01,0.05,0.1,0.3,0.5,0.7$, and $0.9 \mathrm{mmoleN} \mathrm{m^{-3 }}$ for run HLS-ISO. The thicker lines are the contours of the isopycnals. The dotted line shown for run NLS-DEP-F is the mixed layer depth. In run NLS-DEP, phytoplankton is found more abundant and closer to the surface in filaments than within the coherent eddies. Also, the concentration within the cyclone is weaker than within the anticyclone. In run NLS-DEP-F, with an active mixed layer, the small-scale phytoplankton patterns are revealed to the surface. In run HLS-ISO, phytoplankton is found more abundant when isopycnals are doming (within C1) or outcropping (in the north) than in AC1.

$\mathrm{C} 1$ in Figure 8 is of the order of $+100 \mathrm{~m}$ (from 220 to $120 \mathrm{~m}$ ), and is clearly not associated with an upward displacement of the nutrients. The inverse situation is observed within AC1. The vertical displacement of the same isopycnic level is
$-100 \mathrm{~m}(40-140 \mathrm{~m})$, and is not followed by a similar trend in the nutrient surfaces. Such intersections between isopycnals and isonitrate below the euphotic layer have been reported in the Atlantic by Fernandez et al. (submitted manuscript, 2003).

[29] Indeed, although it is widely accepted that mesoscale activity acts to "diffuse" tracers along (coarse grained) isopycnal surfaces, clearly it should not be inferred that tracer and isopycnal patterns should closely resemble one another at the mesoscale and submesoscale. These results illustrate that the signature of raised isopycnals within cyclone $\mathrm{C} 1$ is not the consequence of an upward vertical transport. It is acquired through the horizontal displacement of $\mathrm{C} 1$ from its source waters (the cold side of the front from which it originates) into the warmer environment of the southern side of the front.

[30] On the other hand, there is evidence for the stretching of $\mathrm{C} 1$ and squeezing of $\mathrm{AC} 1$. Again if one follows the depth of the second isopycnic level on Figure 8, it appears that the minimum depth within $\mathrm{C} 1(120 \mathrm{~m})$ is deeper than the basic state in the north $(40 \mathrm{~m})$, and that the maximum depth within AC1 $(140 \mathrm{~m})$ is shallower than the depth of the basic state in the south $(220 \mathrm{~m})$. This shows that cyclone $\mathrm{C} 1$ has actually been stretched down during its formation, and anticyclone $\mathrm{AC} 1$ squeezed up. The squeezing and stretching can also be inferred from the nitrate contours below the euphotic layer. The third contour is deeper in $\mathrm{C} 1(260 \mathrm{~m})$ than in the basic state in the north
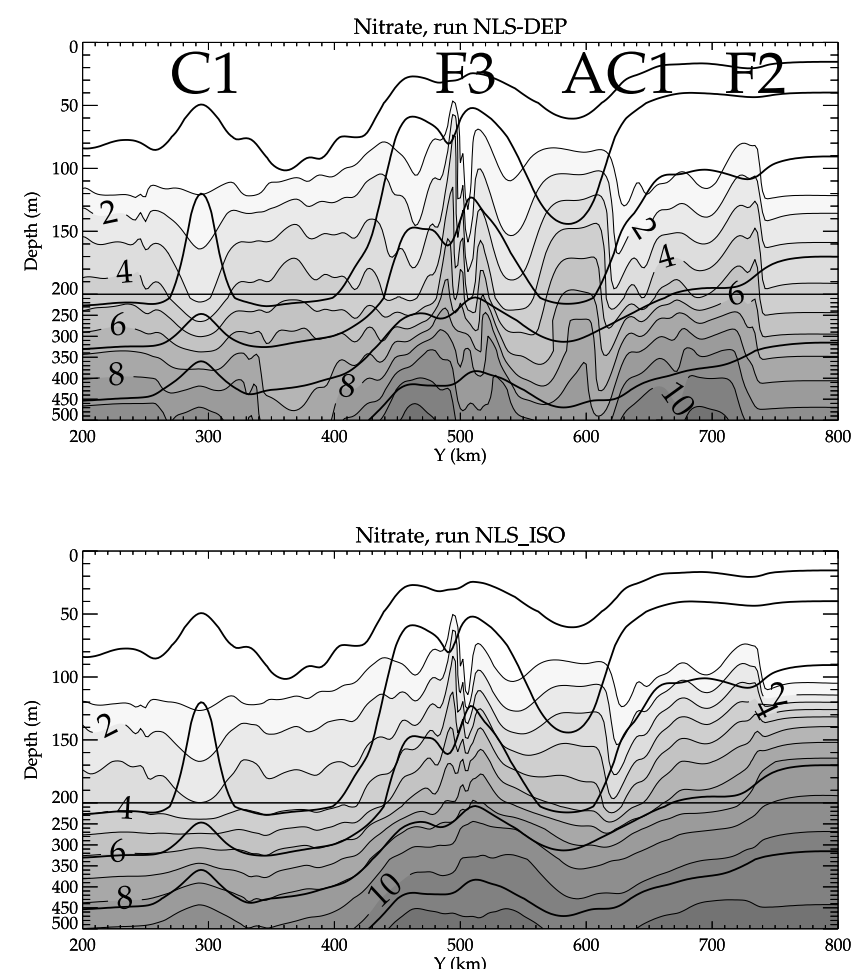

Figure 8. Same as for Figure 7 but for nitrate, and over $500 \mathrm{~m}$ depth. Contour interval is $1 \mathrm{mmoleN} \mathrm{m}{ }^{-3}$. There is no evidence of an uplift of nitrate associated with the isopycnals, even in the case when nitrate initially follows the isopycnal surfaces (run NLS-ISO). 

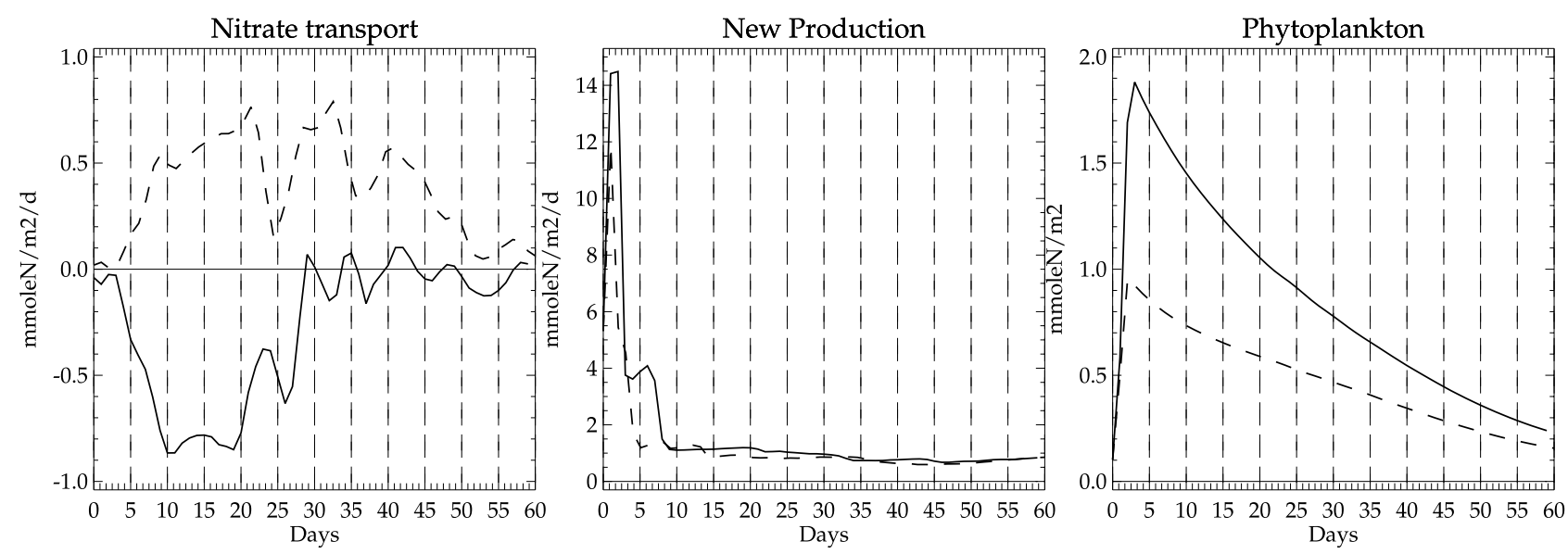

Figure 9. Nitrate transport (advection + diffusion), new production, and phytoplankton for run HLSISO (solid line) and run HLS-DEP (dotted line). Values for nitrate transport and new production are averages over the horizontal domain shown on Figure 1, integrated over the first $100 \mathrm{~m}$ of the water column. Values for phytoplankton are sea surface concentrations averaged over the horizontal domain of Figure 1.

$(190 \mathrm{~m})$ and shallower in $\mathrm{AC} 1(140 \mathrm{~m})$ than in the basic state in the south $(190 \mathrm{~m})$.

\subsubsection{Impact of Weak Convective Mixing}

[31] In run NLS-DEP-F, a buoyancy loss is applied at the surface, reflective of a fall regime. Then, the dynamics are not strictly identical to that of run NLS-DEP. In particular, the mixed layer depth progressively deepens. The primary effect of this forcing is to entrain the phytoplankton subsurface maxima to the surface (Figure 7). The immediate consequence is that phytoplankton submesoscale patterns are revealed to the surface and are now detectable by a satellite.

[32] The deepening of the mixed layer is not homogeneous. At day 42, the mixed layer reaches $80 \mathrm{~m}$ both away from the mesoscale eddy field, and inside some of the mesoscale eddies (Figure 7). However, it remains relatively shallow $(30-40 \mathrm{~m})$ over frontal regions. As investigated by Nurser and Zhang [2000], shallow mixed layers in such conditions are due to the tilting of the isopycnals by the ageostrophic flow, which opposes the destratifying action of the buoyancy loss. Interestingly, the mixed layer in run NLS-DEP-F is shallowest in the same regions of the flow field where phytoplankton subsurface maxima in run NLSDEP are the most intense and the closest to the surface. This results from the phase relationship between vertical velocities and submesoscale fronts [Davies-Jones, 1991; Spall, 1997]. Therefore in run NLS-DEP-F, phytoplankton are first revealed at the surface in these regions of strong stirring. Moreover, the fingerprint of submesoscale phytoplankton patterns at the surface remains strong since the shallowness of the mixed layer inhibits entrainment of deeper waters having low phytoplankton concentrations.

\subsection{Case of the Presence of a Horizontal Large-Scale Nutrient Gradient in the Euphotic Layer}

[33] In Runs HLS-ISO and HLS-DEP, the initial largescale horizontal nutrient gradient injected at the surface leads to a situation very different to that of Run NLS-DEP. At the surface, the available nitrate is consumed in a couple of days, leading to a large phytoplankton bloom (Figure 9).
The horizontal large-scale nutrient gradient is converted into a phytoplankton gradient of the same amplitude (i.e., 3 mmole $\mathrm{m}^{-3}$ in the north and $1 \mathrm{mmole} \mathrm{m}^{-3}$ in the South in Run HLS-ISO, and $0.5 \mathrm{mmole} \mathrm{m}^{-3}$ in the north and $1.5 \mathrm{mmole} \mathrm{m}^{-3}$ in the South in Run HLS-DEP).

[34] In both runs, part of the nitrate that is initially available at the surface is sunk by the triggering of mesoscale activity. On a domain average, this results in an export of nitrate from the surface in Run HLS-ISO, where waters that sink (in the north) are richer in nitrate than waters that rise (in the south) (Figure 9). This result contrasts with the more common view that mesoscale activity brings nutrients to the surface, and illustrates a situation where mesoscale activity can on the contrary decrease total new production. In run HLS-DEP the opposite situation occurs since waters from the south are now richer than waters from the north.

[35] Typical postbloom conditions start with the decline of the new production peak (day 3, Figure 9). During this postbloom period, phytoplankton progressively decrease through mortality and grazing, although it is partly sustained by regenerated production. Its e-folding time is approximately 2 weeks. The nitracline progressively deepens and new production has the same order of magnitude as in run NLS-DEP. New production during the postbloom regime shows the same submesoscale patterns as in oligotrophic conditions, with very energetic small scales. The NP spectra are almost flat in the wave number range 6 to 40 , corresponding to wavelengths comprised between 15 and $150 \mathrm{~km}$ (Figure 3). In these spectra, the approximate same amount of variance resides at mesoscales and at submesoscales. This is not in contradiction with the result that NP is essentially occurring at submesoscales (as can be seen from the plots in physical space, Figure 1). It stems from the fact that submesoscale filaments are organized by the mesoscale eddy field, and therefore contribute to the mesoscale variance. As for run NLS-DEP, the plot of new production versus relative vorticity in run HLS-ISO shows that new production increases in regions of strong negative vorticity (Figure 6). The minimum of new production that is found in run NLS-DEP in regions of zero relative vorticity is not as 
marked in run HLS-ISO. This is because the initial largescale nutrient input is not yet fully consumed, and still sustains a certain amount of new production in all regions. Note also the strong decrease of new production in regions of strongly positive relative vorticities in run HLS-ISO. These are regions where downwelling associated with frontogenesis prevails, and are therefore the regions where nutrients are subducted. High positive vorticities mark also the cyclonic eddy, where sinking results from stretching.

[36] Another important result with respect to runs HLSISO and HLS-DEP is that phytoplankton patterns are totally distinct from new production patterns, and from those in run NLS-DEP (Figure 1). Furthermore, phytoplankton appear to be very well correlated with the mesoscale temperature structures. Correlation coefficients between snapshots of SST and surface phytoplankton range between 0.94 and 0.99 . The spectrum slope of phytoplankton $\left(\mathrm{k}^{-2.4}\right)$ is much steeper than in run $1\left(\mathrm{k}^{-1.4}\right)$, and closer to that of temperature $\left(\mathrm{k}^{-3}\right)$. In run HLS-ISO, the cold cyclonic structure (C1) is associated with high phytoplankton concentrations, and the warm anticyclonic structures (AC1 and $\mathrm{AC} 2)$ with low concentrations. The opposite is true for run HLS-DEP, with the cyclone being poorer than the anticyclones.

[37] In runs HLS-ISO and HLS-DEP the mechanism which leads to spatial variability in the phytoplankton field is simply the direct horizontal cascade [Abraham, 1998]. The variance, initially distributed with a large-scale horizontal gradient, is progressively transferred to smaller and smaller scales. The strong correlation between temperature and phytoplankton also stems from this cascade, since temperature and phytoplankton are initially correlated. In run HLS-ISO, phytoplankton is initially more abundant in the north than it is in the south. Cyclones embody the rich and cold northern waters, and evolve in the poorer waters of the south where they appear as biomass maxima and temperature minima. Inversely, anticyclones embody the poor southern waters and evolve in the north, where they appear as biomass minima and temperature maxima. In run HLS-DEP the opposite situation is found since phytoplankton is initially less abundant in the north than in the south: phytoplankton and temperature are both minimum within cyclones, and maximum within anticyclones.

[38] However the cascade process is not merely horizontal. For instance in run HLS-ISO the phytoplankton concentration within cyclone $\mathrm{C} 1$ is about half that of the concentration of northern waters (Figure 1; the cyclone would appear in red if only horizontal transport was in play). This ensues from the stretching of $\mathrm{C} 1$ during its formation, which leads to the subduction of phytoplankton. Evidence for this subduction is seen the phytoplankton vertical section shown on Figure 7: below the euphotic layer, at $100 \mathrm{~m}$ depth, there is more phytoplankton at the location of $\mathrm{C} 1$ than in its surroundings. Inversely, the two anticyclones are richer than the waters from the south of the front because of squeezing (they would appear as purple on Figure 1 if squeezing was negligible).

\section{Discussion}

\subsection{Eddy Transport Processes}

[39] Results of these simulations illustrate a situation where the raised isopycnals in a cold-core eddy formed by baroclinic instability is not associated with upwelling but rather with downwelling since cold water sinks and warm waters rises in slantwise exchanges. Actually in this situation, cyclones acquire their signature of raised isopycnals through their horizontal displacement into a warmer environment. This is different from the case of eddy pumping, where cyclones are associated with upwelling.

[40] Moreover, as schematized in LKT (see Figure 4 in LKT) and very nicely put forward in the review paper by Williams and Follows [2003], in terms of the conservation of potential vorticity, defined as $(\zeta+f) / h$ (with $\zeta$ the relative vorticity, $f$ the Coriolis parameter and $h$ the thickness of an isopycnic layer), the formation of a cyclone requires an increase in $\zeta$. Hence it must be balanced by an increase of $h$, which corresponds to a stretching of the water column. Since vertical velocity goes to zero at the surface, $\mathrm{h}$ is increased more readily by a lowering of the layer bottom than by a raising of its top. In other words, cyclones, when they result from the baroclinic instability of a mean current, tend to be associated with downwelling.

[41] Once the eddy is formed, and in terms of vertical velocities, the typical feature in the quasi-geostrophic (QG) approximation is a multipolar structure with alternate upwellings and downwellings around the eddies [DaviesJones, 1991; Shearman et al., 2000; Martin and Richards, 2001]. These patterns, which extend down to the zero crossing of the first baroclinic mode (i.e., approximately $1000 \mathrm{~m}$ ), are induced by the curvature of eddy, or by eddyeddy interactions. This is supportive of the idea that upwelling associated with a turbulent mesoscale field occurs at scales smaller than the eddy. This also contrasts eddy pumping, where upwelling is basically on the scale of the eddy.

[42] Close to the surface (down to $200 \mathrm{~m}$ approximately), frontogenesis processes become important [Hoskins and Bretherton, 1972]. Vertical velocities are closely associated with strong vorticity gradients and are characterized by dipolar structures astride these gradients [Spall, 1997; LKT]. This strongly ageostrophic surface dynamics cannot be captured in the frame of the QG approximation, since it involves strong surface density gradients. This explains why it is not seen in modeling studies using QG models [Yoshimori and Kishi, 1994; McGillicuddy et al., 1995; McGillicuddy and Robinson, 1997] nor in modeling studies based on primitive equation models but where the horizontal resolution is not sufficient to accurately resolve these gradients, and the associated submesoscale vertical transport [Mahadevan and Archer, 2000; Oschlies and Garçon, 1998; Oschlies, 2002].

[43] These modeling results and dynamical arguments therefore call into question the efficiency of eddy pumping, as outlined by McGillicuddy et al. [1998], for first-mode eddies resulting from baroclinic instability of a mean current. As discussed before, this situation is common, but certainly not representative of all situations of the open ocean. Moreover, the present model results suggest that the increase in new production occurs on a much smaller scale than previously thought, should the eddy be interacting or not.

[44] Recently, Oschlies [2002] made two critical observations about eddy pumping on the basis of biogeochemical arguments. His first concern is that statistically there is no reason why in situ measurements at long-term time series 
stations should have undersampled the occurrence of eddy events, since the typical sampling intervals (monthly) is similar to the lifetime of the eddy. This argument has indeed been put forward to resolve the apparent discrepancy between indirect geochemical estimates of nutrient supply to oligotrophic subtropical ocean gyres, which tend to be higher than direct measurements [Jenkins, 1988]. Oschlies's [2002] second concern is that a complete picture of eddy pumping has to account not only for uplift and uptake of nutrients, but also for sinking and the subsequent remineralization. Because sinking constitutes a diapycnal transport, remineralization of organic matter occurs on denser and locally deeper isopycnals than its formation. Oschlies [2002] therefore argues that the long-term effect of eddies would be a net deepening of the nutricline to a level at which eddy pumping would cease.

[45] Oschlies's [2002] remarks are interesting arguments to defend the idea that submesoscale events rather than mesoscale events could reconcile direct and indirect estimates of new production in the subtropical gyre of the North Atlantic. First, submesoscale events have shorter space and timescales (day to week, $10 \mathrm{~km}$ ), which inherently makes them more difficult to sample than mesoscale events (months, $100 \mathrm{~km}$ ). Second, unlike eddy pumping, submesoscale upwelling is strongly ageostrophic and constitutes a diapycnal transport that could balance the diapycnal detrital flux.

[46] Regarding the interpretation of observations, correlations between the dynamical signature of an eddy ( $\mathrm{SSH}$, temperature anomaly or sloping isopycnals) and an anomaly in the biogeochemical variables (chlorophyll, nutrients) are often presented as lines of evidence for the occurrence of eddy pumping [McNeil et al., 1999; McGillicuddy et al., 1998, 1999, 2001]. The mechanism outlined by the present model experiments, that eddies created through baroclinic instability can lead to an enhancement of biological activity because of lateral transfer of rich waters, is also in agreement with these observations. Certainly, interpretation of such observations must be handle with care, and knowledge on the history of the eddy is needed.

[47] The importance of the horizontal route for mesoscale nutrient supply is supported by other modeling studies. Garcon et al. [2001] regional budgets computed from an eddy-permitting North Atlantic basin biogeochemical model experiment, show that horizontal nitrate supply to the oligotrophic gyre is larger than vertical transport. The latest budgets by Oschlies [2002] show that vertical eddy advection is the strongest near western boundary currents, where turbulent eddy energy is the highest, whereas eddy supply nutrients predominantly via horizontal advection near the quieter southern and eastern margins of the subtropical gyre. Finally, eddies have also been shown to play an important role in the long-term and large-scale horizontal transport of nutrients [Lee et al., 1997; Lee and Williams, 2000].

[48] The lateral transport emphasized in this study is achieved through the displacement of the eddies away from their formation area. Indeed, contrary to stable waves, eddies carry water parcels with them and have their own displacement dynamics [McWilliams et al., 1986]. Observations of eddies traveling for several months and over hundreds of kilometers, while maintaining the chemical characteristics of their source waters, have been reported [Richardson,
1993; McDonagh and Heywood, 1999]. Provenzale [1999] shows that this horizontal transport by coherent barotropic vortices is possible because they are highly impermeable to inward and outward particle fluxes.

\subsection{Key Parameter: A Large-Scale Nutrient Gradient in the Euphotic Layer}

[49] For this horizontal transfer of nutrients to be effective, the simulations carried in this work clearly show that eddies must originate from a region where there exists a large-scale nutrient gradient in the euphotic layer. When the frontal region where the eddy is formed is also a front between two different biogeochemical regimes, then the biogeochemical properties on one side of the front are transferred to the other side, embedded within mesoscale eddy features.

[50] This mechanism applies to the Gulf Stream rings, since the Gulf Stream separates the rich Slope waters from the poorer Sargasso Sea. Run HLS-ISO is actually qualitatively and quantitatively in good agreement with observations in cold-core and warm-core rings in the Gulf Stream region. $\mathrm{AC} 1$ and $\mathrm{AC} 2$ are good representations of warmcore rings invading the slope waters, and $\mathrm{C} 1$ can be compared with cold-core rings in the Sargasso Sea. Vertical section of nitrate and phytoplankton across C1 (Figures 7 and 8) compare well with the mooring observations around Bermuda [McGillicuddy et al., 1998; McNeil et al., 1999], that show enhanced chlorophyll and nitrate concentrations inside cyclonic eddies. Moreover, as a result of stretching and squeezing, biogeochemical properties within the mesoscale eddies are not exactly those of source waters. They are affected by the vortex stretching and vortex squeezing of the eddies during their formation process. Again, this result is consistent with some observations in Gulf Stream warmcore rings [Hitchcock et al., 1987, 1993] that suggest that phytoplankton biomass and productivity in the warm-core rings can be higher than in the Sargasso Sea.

[51] Although the experiments carried out in this study are rather restricted in parameter space, they raise the question of the efficiency of the lateral transport mechanism in relation with the interdependence of the reaction timescale of the ecosystem and of the timescale for the development and propagation of the coherent physical features. Conceptually, the interplay between the two timescales comes into view by figuring the biological evolution of seeded particles along their lagrangian trajectories. Some of these trajectories are shown in LKT. Floats originating from the northern side of the front eventually end up tracked within the cyclone, while the anticyclone is filled with floats originating from the south. On long timescales, Williams and Follows [1998] suggest that eddies should be quite efficient in transporting DOM, since DOM has long turnover times. On shorter timescales, the transport is more likely to concern phytoplankton (as in run HLS-ISO) or zooplankton (as suggested by Abraham [1998]).

\subsection{Scales of Variability of New Production}

[52] Results of this study emphasize again that the impact of the dynamics involving mesoscale eddies on new production occurs at scales smaller than the mesoscale, in regions where the deformation field is large. Submesoscale dynamics are activated when eddies evolve and interact, or when they eject filaments and decay. These results gener- 
alize the recent findings of LKT, since they are obtained for various biogeochemical regimes, atmospheric forcings, nitrate distribution and during the period of growth and of decay of oceanic eddies.

[53] Direct new production measurements require long incubations, and are difficult to obtain with submesoscale resolution. Attempts to compare new production rates inside and outside of a cyclonic eddy [Allen et al., 1996], are still too coarse to confirm the new production enhancement at the rim of the eddies that is predicted by these model results. Such a task would actually require sampling stations $5 \mathrm{~km}$ apart.

[54] Autoanalyzer systems, mounted on moorings [McNeil et al., 1999] or on towed hydroelectric systems [Prieur et al., 1993] provide high-resolution nitrate measurements, but such data are still very rare. In a frontal region that lies between Almeria and Oran in the in the Mediterranean Sea, Prieur et al. [1993] observe a very narrow (a few kilometers) nitrate peak located below the jet, which is a supporting evidence of submesoscale vertical nutrient injection within the euphotic layer. At a mooring off Bermuda, McNeil et al. [1999] observe short-lived (12 days) episodic nitrate events in May and June 1995, which also supports submesoscale upwelling.

[55] The most important aspect of submesoscale frontogenesis for biogeochemistry is the phase relationship between vertical velocities, regions dominated by strain and regions of strong vorticity gradients [Lapeyre et al., 1999, 2001]. Submesoscale upwelling occurs in regions of strong vorticity gradients, which are regions of strong surface shear. The upwelled nutrients, once brought to the surface, are elongated in thin filaments along those shears. Complementary evidence for the importance of horizontal stirring is provided by Martin et al. [2002], who used a 2D turbulence model forced with a parameterization for localized nitrate upwelling to show that dispersion at the surface by the turbulence field can increase new production.

\subsection{Scales of Variability of Phytoplankton}

[56] These modeling results show that phytoplankton variability can actually be quite different than the variability of new production. This result stems from the different $e$-folding times of phytoplankton and new production. In a nutrient stressed environment, new production responds almost instantaneously to inputs of nutrients and is therefore always governed by vertical advection. Phytoplankton on the other hand can persist for a couple weeks, the time necessary for the turbulent cascade to transfer variance from the large scale to the mesoscale.

[57] When nutrients are depleted from the surface, phytoplankton growth mostly results from submesoscale nutrient injection. Therefore phytoplankton distribution resembles that of new production, and is also dominated by submesoscale features. There is no obvious correlation with temperature, which is dominated by mesoscale variability. Rather, phytoplankton are found in regions of strong sea surface vorticity gradients, where frontogenesis is active. This case is illustrated by runs NLS-DEP, NLSISO, and NLS-DEP-F. There is some observational evidence of this type of situation. Hitchcock et al. [1987], during a series of transects across the Gulf Stream, found a chlorophyll maximum located at the periphery of a warmcore ring. Perez et al. [2003] observe similar features in a summer cruise to the Azores front region. Strass [1992], using a towed undulating vehicle in the North Atlantic during summer finds patches of high chlorophyll concentration at scales of $10-20 \mathrm{~km}$. Most of all, high-resolution sea color images [Garcia-Moliner and Yoder, 1994; Yoder, 2000; Abraham et al., 2001; Longhurst, 2001; Mahadevan and Campbell, 2002; Davenport et al., 2002; Santoleri et al., 2003] clearly reveal spatial variability of phytoplankton at the submesoscale. As shown in run NLS-DEP-F, the submesoscale phytoplankton patterns, that are produced essentially below the surface, can indeed be exposed to the surface when the mixed layer is active.

[58] However, when a large-scale nutrient (and/or phytoplankton) gradient exists at the surface, then submesoscale frontal regions primarily appear as a transition zone between rich and poor waters, rather than a local biomass maximum. In this situation, phytoplankton distribution is dominated by mesoscale variability and is anticorrelated with temperature. Such a close correspondence between the mesoscale temperature and pigment field structures was observed in satellite imagery of the Gulf Stream [Garcia-Moliner and Yoder, 1994] and Sargasso Sea [McGillicuddy et al., 2001].

[59] The scenarios presented here are different from that of Mahadevan and Campbell [2002], who conclude from a passive tracer transport/reaction model, that phytoplankton is more patchy than temperature because the response of phytoplankton to the availability of nutrients is faster than the equilibration of temperature to atmospheric heat fluxes. Abraham [1998], like LKT, indicates phytoplankton is more patchy than temperature when its initial conditions differ from that of temperature. This is because the thermal wind balance prohibits the formation of energetic small scales of density [Klein et al., 1998]. In the Mahadevan and Campbell [2002] scenario, temperature is allowed to develop small scales, corresponding to a situation where temperature and density are strongly decoupled [Klein et al., 1998]. Incidentally, phytoplankton patchiness may also result from biological processes alone, as shown by the modeling study of Popova et al. [2002].

\subsection{Subduction}

[60] This study also provides evidence that subduction of organic matter at submesoscale is an important export pathway. This can be seen on the vertical sections of phytoplankton (Figure 7) which shows the presence of biomass below the euphotic layer, located in thin filaments. Since phytoplankton are neutrally buoyant in the model, downwelling velocities are responsible for this subductive export. Plots of this downwelled biomass against surface relative vorticity (not shown) reveal that subduction mainly occurs in regions of high positive vorticities, which are indeed regions where downwelling velocities due to frontogenesis processes occur.

[61] In all experiments, this dynamical transport has the same order of magnitude as the more traditional export through fast sinking particles. However, characteristics of these two export pathways are very different. The dynamical export is much faster; it follows by only a few days the new production peak, while biological export is delayed by 1-2 months (the time taken by the zooplankton to grow). They also feed different water masses: the dynamical export feeds the intermediate $100-300 \mathrm{~m}$ of the water column (i.e., 
just below the nitracline), while export of sinking particles is to much deeper depths. This suggests that submesoscale dynamical export might play a role in the depth of the nitracline and the vertical gradient of nitrate in the large scale. Evidence of such dynamical export has been reported at a Mediterranean front [Prieur et al., 1993]. It differs from dynamical export associated with storm events and changing mixed layer depths [Stramska et al., 1995; Koeve et al., 2002].

[62] Another important finding is the possible decrease of total new production due to mesoscale dynamics. Following a large-scale nutrient injection, some of the nutrients made available can be subducted prior to being used for photosynthesis. A possible consequence is that coarse-resolution models, that are generally thought to underestimate new production because they misrepresent the action of the eddies [Oschlies and Garçon, 1998; Aumont et al., 2003], can actually occasionally overestimate it.

\section{Conclusion}

[63] This study investigates specific transport mechanisms that induce variability of phytoplankton and new production on scales of $2-100 \mathrm{~km}$ in temperate and subtropical regions of the ocean, and relates these mechanisms to the large-scale nutrient environment. It is shown that observations consistent with eddy pumping (i.e., correlation between doming isopycnals and increased biology) are also consistent with another mechanism, that involves a horizontal route for transport. Furthermore, nutrients are shown to not necessarily follow isopycnal surfaces at the mesoscale, although this could be true at larger scales.

[64] These results then stress the importance of the biogeochemical environment in the region where the eddies are formed. Two distinct regimes are rationalized, in terms of the large-scale distribution of nutrients. The model setup provides a schematic representation of these two regimes. When horizontal gradients are dominant, the regime is that of the direct horizontal cascade (Abraham's [1998] scenario). In that case, phytoplankton and temperature are correlated at the mesoscale if the large-scale gradient of nutrients coincides with that of temperature. In such a regime, high-resolution satellite maps of chlorophyll and temperature should show significant correlations. When vertical gradients are dominant, the regime is that of the small scale nutrient injection (LKT). The small scales of phytoplankton are more energetic, and phytoplankton is correlated with vorticity rather than temperature. In both regimes, new production is mainly driven by small-scale vertical advection.

[65] Another important aspect revealed by the numerical results is the small-scale subduction triggered by the flow. Subduction can affect both organic material, and therefore contribute to the export, as well as inorganic nutrients, and thus decrease new production.

[66] Results of this study apply to first-mode baroclinic eddies produced by baroclinic instability, which constitute a large part of the total eddy variability [Stammer, 1997, 1998]. Regionally, other sorts of eddies may dominate, such as $18^{\circ}$ mode water eddies [Brundage and Dugan, 1986], so-called submesoscale coherent vortices [McWilliams, 1985], eddies created in the lee of islands [Falkowski et al., 1991], Von Karman vortex or eddies resulting from wind stress circulation patterns, and these deserve more specific analysis. Other open ocean situations that remain to be explored concern the interaction between a large number of eddies, and the long term effect of seasonal and intermittent atmospheric forcing over an eddy field. In these situations, eddy pumping has been shown to prevail [McGillicuddy et al., 1999], and further regional studies at higher resolution should enable to quantify the relative importance of horizontal transport, eddy pumping and submesoscale vertical transport.

[67] Also, not all aspects of the coupling between the eddy activity and the distribution of nutrients in the ocean are addressed in this study. It is shown how the large-scale distribution of nutrients affects the variability of phytoplankton. It is also suggested that in turn, subduction of organic material through small-scale advection could be a significant source for remineralization below the euphotic layer. What remains to be explored are the effects of the small-scale distribution of nutrients. As mentioned before, nutrients may not follow the isopycnal surfaces at the mesoscale. Below the euphotic layer, it can be considered as a passive tracer at a first order, and therefore displays more energetic small scales than does density [Klein et al., 1998]. These small scales should impact the variability of phytoplankton when injected through convection.

[68] Acknowledgments. Patrice Klein is thanked for his extremely valuable comments, Riadh Elloumi for conducting preliminary experiments, David Straub, Albert Fischer, and Keith Rodgers for their careful reading of the manuscript. Three anonymous reviewers are thanked for their very constructive criticisms, questions and suggestions, that helped to improve the manuscript. The OPA system team is thanked for maintaining the OPA code. Graphic outputs and diagnostics were performed with the SAXO graphic tools developed by Sebastien Masson. Funding for this study was provided by the French Ministère de la Recherche (through the ACI program) and the CNRS (through the PROOF program). The experiments were carried out on the NEC SX-5 of the IDRIS center.

\section{References}

Abraham, E. R., The generation of plankton patchiness by turbulent stirring, Nature, 391, 577-580, 1998 .

Abraham, E. R., C. S. Law, P. W. Boyd, S. J. Lavender, M. T. Maldonado, and A. R. Bowie, Importance of stirring in the development of an ironfertilized phytoplankton bloom, Nature, 407, 727-730, 2001.

Allen, C. B., J. Kanda, and E. A. Laws, New production and photosynthetic rates within and outside a cyclonic mesoscale eddy in the North Pacific subtropical gyre, Deep Sea Res., Part I, 43, 917-936, 1996.

Arhan, M., A. Colin de Verdire, and L. Memery, The eastern boundary of the subtropical North Atlantic, J. Phys. Oceanogr., 24, 1295-1316, 1994.

Aumont, O., E. Maier-Reimer, S. Blain, and P. Monfray, An ecosystem model of the global ocean including $\mathrm{Fe}, \mathrm{Si}, \mathrm{P}$ co-limitations, Global Biogeochem. Cycles, 17(2), 1060, doi:10.1029/2001GB001745, 2003.

Brundage, W. L., and J. P. Dugan, Observations of an anticyclonic eddy of $18^{\circ}$ mode water in the Sargasso Sea, J. Phys. Oceanogr., 16, 717-727, 1986.

Davenport, R., S. Neur, P. Helmke, J. Perez-Marrero, and O. Llinas, Primary production in the northern Canary Islands region as inferred from SeaWiFS imagery, Deep Sea Res., Part II, 49, 3481-3496, 2002.

Davies-Jones, R., The frontogenetical forcing of secondary circulations. part I: The duality and generalization of the Q vector, J. Atmos. Sci., 48, 497-509, 1991.

Falkowski, P. G., D. Kiemann, Z. Kolber, and P. K. Bienfang, Role of eddypumping in enhancing primary production in the ocean, Nature, $352,55-$ 58,1991 .

Garcia-Moliner, G., and J. A. Yoder, Variability in pigment concentration in warm-core rings as determined by coastal zone color scanner satellite imagery from the Mid-Atlantic Bight, J. Geophys. Res., 99, 14,27714,290, 1994

Garcon, V. C., A. Oschlies, S. C. Doney, D. McGillicuddy, and J. Waniek, The role of mesoscale variability on plankton dynamics in the North Atlantic, Deep Sea Res., Part II, 48, 2199-2226, 2001. 
Glover, D. M., and P. G. Brewer, Estimates of wintertime mixed-layer nutrient concentrations in the North Atantic, Deep Sea Res., Part A, $35,1525-1546,1988$.

Glover, D. M., S. C. Doney, A. J. Mariano, R. H. Evans, and S. J. McCue, Mesoscale variability in time series data: Satellite-based estimates from the US JGOFS Bermuda Atlantic Time-Series Study (BATS) site, J. Geophys. Res., 107(C8), 3092, doi:10.1029/2000JC000589, 2002.

Held, I. M., R. T. Pierrehumbert, S. T. Garner, and K. L. Swanson, Surface quasi-geostrophic dynamics, J. Fluid Mech., 282, 1-20, 1995.

Hitchcock, G. L., C. Langdon, and T. J. Smayda, Short-term changes of a Gulf Stream warm-core ring: Phytoplankton biomass and productivity, Limnol. Oceanogr., 32, 919-928, 1987.

Hitchcock, G. L., A. J. Mariano, and T. Rossby, Mesoscale pigment fields in the Gulf Stream: Observations in a meander crest and trough, J. Geophys. Res., 98, 8425-8445, 1993.

Hoskins, B. J., and F. P. Bretherton, Atmospheric frontogenesis models: Mathematical formulation and solution, J. Atmos. Sci., 29, 11-37, 1972.

Jenkins, W. J., Nitrate flux into the euphotic zone near Bermuda, Nature, 300, 246-248, 1988.

Klein, P., and L. Hua, The mesoscale variability of the sea surface temperature: An analytical and numerical model, J. Mar. Res., 48, 729-763, 1990.

Klein, P., A.-M. Treguier, and L. Hua, Three-dimensional stirring of thermohaline fronts, J. Mar. Res., 56, 589-612, 1998.

Koeve, W., F. Pollehne, A. Oschlies, and B. Zeitzschel, Storm induced convective transport of suspended matter during a spring bloom in the northeast Atlantic, Deep Sea Res., Part I, 49, 1431-1444, 2002.

Lapeyre, G., P. Klein, and B. L. Hua, Do tracer gradient vectors align with strain vectors in 2-D flows?, Phys. Fluids, 11, 3729-3737, 1999.

Lapeyre, G., B. L. Hua, and P. Klein, Dynamics of the orientation of active and passive scalars in two-dimensional turbulence, Phys. Fluids, 13, $251-254,2001$.

Lee, M. M., and R. G. Williams, The role of eddies in the isopycnic transfer of nutrients and their impact on biological production, J. Mar. Res., 58, 895-917, 2000.

Lee, M. M., D. P. Marshall, and R. G. Williams, On the eddy transfer of nutrients: Advective or diffusive?, J. Mar. Res., 55, 483-505, 1997.

Lévy, M., P. Klein, and A.-M. Treguier, Impacts of sub-mesoscale physics on phytoplankton production and subduction, J. Mar. Res., 59, 535-565, 2001.

Longhurst, A., A major seasonal phytoplankton bloom in the Madagascar Basin, Deep Sea Res., Part I, 48, 2413-2422, 2001.

Madec, G., P. Delecluse, M. Imbard, and C. Lévy, OPA 8.1 Ocean General Circulation Model Reference Manual, in Note Scientifiques du Ple de Modlisation, Inst. Pierre-Simon Laplace, Paris, 1999. (Available as http://www.ipsl.jussieu.fr.)

Mahadevan, A., and D. Archer, Modeling the impact of fronts and mesoscale circulation on the nutrient supply and biogeochemistry of the upper ocean, J. Geophys. Res., 105, 1209-1225, 2000.

Mahadevan, A., and J. W. Campbell, Biogeochemical patchiness at the sea surface, Geophys. Res. Lett., 29(19), 1926, doi:10.1029/2001GL014116, 2002.

Mariotti, A., B. Legras, and D. G. Dritschel, Vortex stripping and the erosion of coherent structures in two-dimensional flows, Phys. Fluids, 6, 3954-3962, 1994

Martin, A. P., and K. J. Richards, Mechanisms for vertical nutrient transport within a North Atlantic mesoscale eddy, Deep Sea Res., Part II, 48, $757-$ 773, 2001.

Martin, A. P., K. J. Richards, A. Bracco, and A. Provenzale, Patchy productivity in the open ocean, Global Biogeochem. Cycles, 16(2), 1025, doi:10.1029/2001GB001449, 2002.

McDonagh, E. L., and K. J. Heywood, The origin of an anomalous ring in the southeast Atlantic, J. Phys. Oceanogr., 29, 2050-2064, 1999.

McGillicuddy, D., Jr., and A. R. Robinson, Eddy-induced nutrient supply and new production in the Sargasso Sea, Deep Sea Res., Part I, 44, $1427-1450,1997$.

McGillicuddy, D., Jr., A. R. Robinson, and J. J. McCarthy, Coupled physical and biological modeling of the spring bloom in the North Atlantic (II): Three dimensional bloom and post-bloom processes, Deep Sea Res., Part I, 42, 1359-1398, 1995.

McGillicuddy, D., Jr., A. R. Robinson, D. A. Siegel, H. W. Jannasch, R. Johnson, T. D. Dickey, J. McNeil, A. F. Michaels, and A. H. Knap, Influence of mesoscale eddies on new production in the Sargasso Sea, Nature, 394, 263-265, 1998.

McGillicuddy, D. J., R. Johnson, D. A. Siegel, A. F. Michaels, N. R. Bates, and A. H. Knap, Mesoscale variations of biogeochemical properties in the Sargasso Sea, J. Geophys. Res., 104, 13,381-13,394, 1999.
McGillicuddy, D. J., V. K. Kosnyrev, J. P. Ryan, and J. A. Yoder, Covariation of mesoscale ocean color and sea-surface temperature patterns in the Sargasso Sea, Deep Sea Res., Part II, 48, 1823-1836, 2001.

McNeil, J. D., H. W. Jannasch, T. Dickey, D. McGillicuddy, M. Brzezinski, and C. M. Sakamoto, New chemical, bio-optical and physical observations of upper ocean response to the passage of a mesoscale eddy off Bermuda, J. Geophys. Res., 104, 15,537-15,548, 1999.

McWilliams, J. C., Submesoscale, coherent vortices in the ocean, Rev. Geophys., 23, 165-182, 1985.

McWilliams, J. C., P. R. Gent, and N. J. Norton, The evolution of balanced, low-mode vortices on the beta-plane, J. Phys. Oceanogr., 16, 838-855, 1986.

Nurser, A. J. G., and J. W. Zhang, Eddy-induced mixed layer shallowing and mix layer/thermocline exchange, J. Geophys. Res., 105, 21,85121,868, 2000.

Oschlies, A., Can eddies make ocean deserts bloom?, Global Biogeochem. Cycles, 16(4), 1106, doi:10.1029/2001GB001830, 2002.

Oschlies, A., and V. Garçon, Eddy-induced enhancement of primary production in a model of the North Atlantic Ocean, Nature, 394, 266-269, 1998.

Paillet, J., Central water vortices of the eastern North Atlantic, J. Phys. Oceanogr., 10, 2487-2503, 1999

Pelegri, J. L., and G. T. Csanady, Nutrient transport and mixing in the Gulf Stream, J. Geophys. Res., 96, 2577-2583, 1991.

Perez, F. F., M. Gil-Coto, and A. F. Rios, Large and mesoscale variability of the water masses and the deep chlorophyll maximum in the Azores front, J. Geophys. Res., 108(C7), 3215, doi:10.1029/2000JC000360, 2003.

Pinca, S., and M. E. Huntley, Spatial organization of particle size composition in an eddy-jet system off California, Deep Sea Res., Part I, 47, $973-$ 996, 2000.

Pollard, R. T., and L. A. Regier, Vorticity and vertical circulation at an ocean front, J. Phys. Oceanogr., 22, 609-625, 1992.

Popova, E. E., C. J. Lozano, M. A. Srokosz, M. J. R. Fasham, P. J. Haley, and A. R. Robinson, Coupled 3D physical and biological modeling of the mesoscale variability observed in north-east Atlantic in spring 1997: Biological processes, Deep Sea Res., Part I, 49, 1741-1768, 2002.

Prieur, L., C. Copin-Montegut, and H. Claustre, Biophysical aspects of "Almofront-1", an intensive study of a geostrophic frontal jet, Ann. Inst. Oceanogr., 1, 69-86, 1993.

Provenzale, A., Transport by coherent barotropic vortices, Annu. Rev. Fluid Mech., 31, 55-93, 1999.

Richardson, P. L., Gulf Stream rings, in Eddies in Marine Science, chap. 2, pp. 19-45, edited by A. R. Robinson, Springer-Verlag, New York, 1983. Richardson, P. L., A census of eddies observed in North Atlantic SOFAR float data, Prog. Oceanogr., 31, 1-50, 1993.

Santoleri, R., V. Banzon, S. Marullo, E. Napolitano, F. D’Ortenzio, and R. Evans, Year-to-year variability of the phytoplankton bloom in the southern Adriatic Sea (1998-2000): Sea-viewing Wide Field-of-view Sensor observations and modeling study, J. Geophys. Res., 108(C9), 8122, doi:10.1029/2002JC001636, 2003.

Shearman, R. K., J. A. Barth, J. S. Allen, and R. L. Haney, Diagnosis of the three-dimensional circulation in mesoscale features with large Rossby number, J. Phys. Oceanogr., 30, 2687-2709, 2000.

Spall, M. A., Frontogenesis, subduction, and cross-front exchange at upper ocean fronts, J. Geophys. Res., 100, 2543-2557, 1995.

Spall, M. A., Baroclinic jets in confluent flow, J. Phys. Oceanogr., 27, 1054-1071, 1997.

Spall, M. A., Generation of strong mesoscale eddies by weak ocean gyres, J. Mar. Res., 58, 97-116, 2000.

Spall, S. A., and K. J. Richards, A numerical model of mesoscale frontal instabilities and plankton dynamics-I. Model formulation and initial experiments, Deep Sea Res., Part I, 47, 1261-1301, 2000.

Stammer, D., Global characteristics of ocean variability from regional TOPEX/Poseidon altimeter measurements, J. Phys. Oceanogr., 27, 1743-1769, 1997.

Stammer, D., On eddy characteristics, eddy transports and mean flow properties, J. Phys. Oceanogr., 28, 727-739, 1998.

Stramska, M., T. Dickey, J. Marra, A. Plueddemann, C. Langdon, and R. Weller, Bio-optical variability associated with phytoplankton dynamics in the North Atlantic ocean during spring and summer of 1991, J. Geophys. Res., 100, 6605-6619, 1995.

Strass, V. H., Chlorophyll patchiness caused by mesoscale upwelling at fronts, Deep Sea Res., Part A, 39, 75-96, 1992.

Wang, D.-P., Model of frontogenesis: Subduction and upwelling, J. Mar. Res., 51, 497-513, 1993.

Williams, R. G., and M. J. Follows, Eddies make ocean deserts bloom, Nature, 394, 228-229, 1998.

Williams, R. G., and M. J. Follows, Physical transport of nutrients and the maintenance of biological production, in Ocean Biogeochemistry: A JGOFS synthesis, edited by M. Fasham, Springer, New York, 2003. 
Wunsch, C., The vertical partition of oceanic horizontal kinetic energy and the spectrum of global variability, J. Phys. Oceanogr., 27, 1770-1794, 1997.

Yentsch, C. S., and D. A. Phinney, Rotary motions and convection as a means of regulating primary production in warm core rings, J. Geophys. Res., 90, 3237-3248, 1985.

Yoder, J. A., An overview of temporal and spatial patterns in satellitederived chlorophyll- $a$ imagery and their relation to ocean processes, in Satellites, Oceanography and Society, edited by D. Halpern, chap. 12, pp. 225-238, Elsevier Sci., New York, 2000.
Yoshimori, A., and M. J. Kishi, Effects of interaction between two warmcore rings on phytoplankton distribution, Deep Sea Res., Part I, 41, $1039-1052,1994$.

M. Lévy, LODYC, IPSL, UPMC, BC100 4, place Jussieu, 75252 Paris Cedex 05, France. (marina.levy@lodyc.jussieu.fr) 

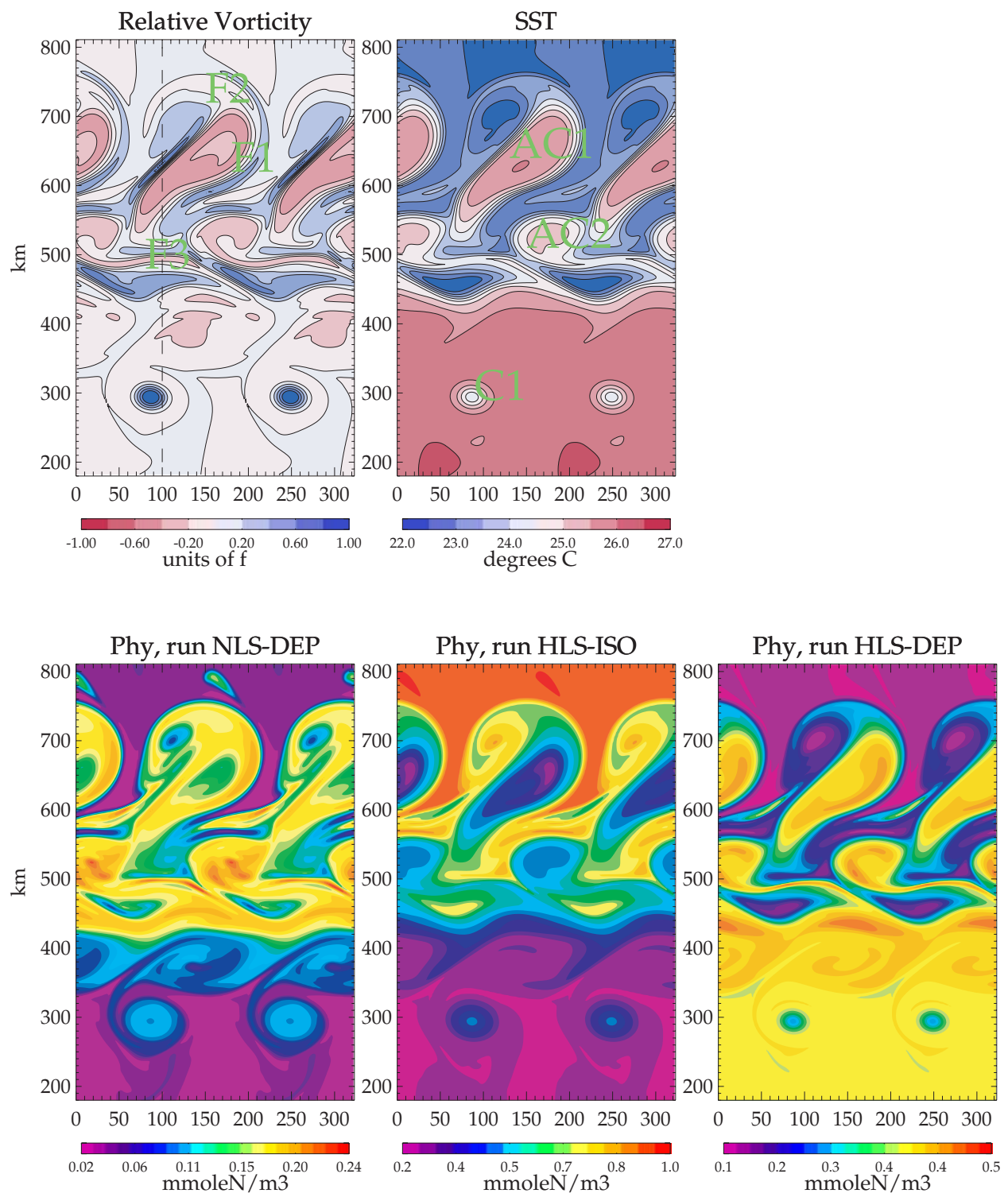

Figure 1. Model snapshots at day 42. For clarity and taking advantage of the zonal periodicity the domain is artificially doubled in length in its zonal direction. Meridional bands $0-200$ and $800-1000 \mathrm{~km}$ are not affected by the eddies and are withdrawn from the analysis. Surface fields are shown, except for "Phy, run NLS-DEP", which shows the phytoplankton concentration averaged over the depth range 0$100 \mathrm{~m}$. The same dynamics are used in runs NLS-DEP, HLS-ISO, and HLS-DEP. The differences in the resulting distribution of phytoplankton are related to different nitrate initializations. Note that the space scales of variability of temperature (density) and relative vorticity are quite different. In run NLS-DEP, phytoplankton space variability resembles that of vorticity (i.e., dominated by submesoscale features), while in runs HLS-ISO and HLS-DEP, it resembles the variability of SST (i.e., dominated by mesoscale features). 